Research Article

\title{
Energy Efficiency Enhancement and Climate Change Mitigations of SMEs through Grid-Interactive Solar Photovoltaic System
}

\author{
G. N. Lalith Pankaj Raj (iD) and V. Kirubakaran $(\mathbb{D}$ \\ Centre for Rural Energy, The Gandhigram Rural Institute-Deemed to be University, Gandhigram, 624302 Tamil Nadu, India \\ Correspondence should be addressed to V. Kirubakaran; kirbakaran@yahoo.com
}

Received 26 November 2020; Revised 5 January 2021; Accepted 8 January 2021; Published 27 January 2021

Academic Editor: S. Shanmuga Priya

Copyright (c) 2021 G. N. Lalith Pankaj Raj and V. Kirubakaran. This is an open access article distributed under the Creative Commons Attribution License, which permits unrestricted use, distribution, and reproduction in any medium, provided the original work is properly cited.

\begin{abstract}
According to the International Energy Agency's estimation, Indian primary energy demand is expected to increase by about 1250 Mtoe and 1500 Mtoe by 2030 . The $3 \mathrm{M}$ management concept now changed into a $4 \mathrm{M}$ management concept that includes energy management. In the case of energy management, the electrical energy sector assumes critical importance. An energy cost occupies nearly $30-40 \%$ of the production cost in small and medium-size enterprises (SMEs). Bureau of Energy Efficiency (BEE) has initiated a separate energy efficiency intervention to the SME's, where the energy-efficient technologies, operational procedures, and proper awareness programs to SMEs are stated. This paper discusses the complete electrical energy audit on a small-scale Siddha and Ayurveda medicine industry. The traditional medicine manufacturing technologies make the process complex (process loads are intermittent/interlinked) during analysis. Hence, the detailed energy auditing/conservation studies on the power factor/harmonics were carried out without affecting Indian traditional medicine manufacturing technology. The postauditing design and installation of an intelligent controller by considering the intermittent/interlinked loads are carried out, and the effectiveness of the intelligent controller is ascertained with the energy conservation and the carbon emission reduction of SME. In addition, the climate change mitigation is ensured through the design and deployment of grid-interactive rooftop solar photovoltaic power plant using Solar Pro v4.5 (Photovoltaic System simulation software) with the power analysis, economic analysis and life cycle carbon emission of the proposed plant. The proposed solar photovoltaic power plant ensures energy self-sufficiency and sustainable energy utilization by carbon emission reduction on electricity utilization of SMEs.
\end{abstract}

\section{Introduction}

According to the Ministry of Environment and Forests (MOEF), $70 \%$ of the total industrial pollution of the whole nation (INDIA) is due to SMEs [1]. The Bureau of Energy Efficiency (BEE) has initiated the energy efficiency interventions in selected 25 SME clusters during the XI plan. During the XII plan, implementations of 100 technology demonstration real-time projects in five SME sectors envisaged facilitating large-scale replication of the successful technology. As per Energy Conservation Act, 2001, energy audit is defined as verification, monitoring, and analysis of the use of energy, including submission of technical report containing recommendations for improving energy efficiency with cost-benefit analysis and an action plan to reduce energy consumption. Energy auditing is a systematic approach for energy management and the first step in realizing the energy efficiency opportunities [2] with economic [3] consideration. The industrial energy audit is mainly focusing on the energy loss reduction [4] in the following aspects of the process, the operation modification, investment in energy-efficient technologies, load management, and conversion energy losses. 
The power quality is a catchword that came into the power industry during the 1980s. According to the Institute of Electrical and Electronics Engineers (IEEE) standard IEEE 1100 , power quality is "the concept of powering and grounding sensitive electronic equipment in a manner suitable for the equipment." The device may be anything; they will respond adversely towards the power quality issues. According to EDSA, power analytics ensuring business resilience, "30 to $40 \%$ of all business downtime is closely associated with power quality problems" [5]. Businesses have many expensive investments towards the office, production equipment, and infrastructures. Power quality protection is a low-cost insurance policy against power wastage and accidents.

This paper deals with the objective of attaining the state of energy self-sufficient SME, and the quest for energy selfsufficiency commences once the conventional power grid is volatile and unreliable. The dependence on the conventional power grid will reduce the industry's overall productivity due to various constraints like peak time shutdown, off-peak time of operation, and high tariff with lower power quality. The paradigm shift from the conventional power grid to a nonconventional (renewable) power grid could address the issue and increase overall industrial productivity. Therefore, energy self-sufficiency is highly recommended for increasing productivity with less carbon emission through renewable energy resources.

This paper deals with the electrical anomalies that are pertaining to the power quality issues faced by a mediumscale Siddha and Ayurveda manufacturing enterprise in the complete electrical energy auditing perspective. The reflection of low power quality shows an increase in the electricity bill of the enterprise. This paper also deals with the postaudit proposal of grid-interactive solar photovoltaic (SPV) power plant for attaining the state of energy self-sufficiency of the SMEs using the Solar Pro simulation software, and it is a roadmap for climate change mitigation by carbon emission reduction.

\section{Literature Review}

The various forms of the power factor improvement in an SME unit with the underlying design calculations for power capacitors and various power quality issues in a process industry were discussed [6]. The clarity about the overall audit process of textile industry motors in turn helps us to study the old induction-type motor loads in this SME [7, 8]. The process mapping of an industrial production process is a critical area that has to be taken care of to start up with the process, which helped us create a roadmap to start with the SME audit process under investigation [9].

The various economic aspects from the point of top-level management people, to implement the various collective recommendations by the electrical service company (ESCO), Industrial Assessment Centres (IAS), helped in making suggestions and recommendations for this SME [10]. The presence of power quality issues in the food processing industry was addressed, which gave clarity in the power factor capacitor's design to act as a harmonic filter to counter-effect the harmonics generated in the industry [11]. The author focused on the practical challenges in the environmental management of the Indian SMEs and its methodologies to address the environmental issues by considering the country's need and sector-specific investigation for identifying the relationship between the small SMEs [12]. The detailed energy and economic analysis for energy conservation measures help SME's energy auditing with detailed cost economics $[3,13]$.

The energy audit is a consistent and useful tool for overcoming technological, information bottlenecks, and investment in energy-efficient measures [2]. The measurement [14] of data as a primary data collection is to understand the operation and event occurrence, calculate, explain, and validate the industry's energy consumption. The energy auditing tool [15] of Passive Home Planning Package (PHPP) and Transient System Simulation (TRNSYS) are used for energy estimation, and equivalent energy savings with greater accuracy and machine learning [16] algorithms are used for energy self-sufficiency. The effectiveness of energy audit diminishes with the number of employees increasing in the organizational size [17] in lighting, heating, insulation, and operations. The energy selfsufficiency [18] of SME is ensured by installing the SPV power plant with the sensitivity analysis of factors pertaining to the technical and economic consideration. The country's energy self-sufficiency and energy security is achieved by the $100 \%$ renewable energy transition based on the country's energy demand [19]. The renewable energy resource without or with negligible energy storage [20] is highly economical for attaining the state of energy self-sufficiency.

The solar PVsyst simulation software is used for designing the SPV plants in vessels [21]. The power and energy analysis of the designed SPV plant is carried out by the PVsyst software based on the vessel's route. The location-specific [22] solar potential and its performance can be analyzed using the PVsyst software. The $15 \mathrm{kWp}$ grid-interactive SPV [23] is designed and simulated using the PVsyst software with the annual average performance ratio (PR) of $79.48 \%$.

The design and performance analysis of $2 \mathrm{kWp}$ SPV gives $73.5 \%$ with the PVsyst [24] simulation software in India's Odisha state. The economic analysis gives a payback period of 7.6 years. The annual average PR of $200 \mathrm{kWp}$ simulated SPV plant is $81.7 \%$. The real-time comparative analysis of performance ratio [25] ranges between $60 \%$ and $90 \%$, and capacity utilization factor (CUF) ranges from $12 \%$ to $18 \%$ for the rooftop $20 \mathrm{kWp}$ SPV power plant in the Telangana state of India. The design and performance analysis of $100 \mathrm{kWp}$ Si-poly [26] SPV plant is carried out using the PVsyst simulation software. The annual average PR of $80 \%$ with a power generation of $165.38 \mathrm{MWh}$ is achieved in the designed SPV plant.

The Solar Pro simulation software has a tremendous amount of metro [27] database for various global parts. Also, the interface for manual addition of the measured dataset makes the software more user-friendly and has greater accuracy. The design and performance analysis of $100 \mathrm{kWp}$ SPV is carried out using the Solar Pro simulation software in the Telangana state of India. The Solar Pro simulation software is used for shadow analysis of the SPV plant. The seasonal tilt (or) inclination angle [27] for module mounting is calculated based on the field conditions using Solar Pro and 
obtained $30791.64 \mathrm{kWh} /$ year for building energy performance enhancement. The Solar Pro software is used for $3.15 \mathrm{kWp}$ SPV plant design and its fault characteristics [28] study during the faulty condition. The design and development of circuitbased solar module performance on shadow and faulty condition and its validity is verified using the Solar Pro simulation software package. The maximum power point (MPP) error of $10.17 \%$ [29] is recorded during the effectiveness comparison of the circuit-based module and Solar Pro simulator.

From the review, SMEs have significant energy efficiency enhancement scope by enhancing the system's power quality. In addition, due to the various positive indices in the installation of SPV power plant in SMEs for attaining the state of energy self-sufficiency and climate change mitigation, the various commercial and noncommercial solar design and simulation packages are available. The Solar Pro v4.5 (Photovoltaic System simulation software) is used for obtaining an interactive $3 \mathrm{D}$ user interface for shading and designing panel mounting with more significant space and power optimization. It is also highly recommended for its unique features of calculation for shading and power analysis with minuteby-minute accuracy. Therefore, the proposed SPV's design and performance prediction is carried out by Solar Pro v4.5 (Photovoltaic System simulation software).

\section{Methodology}

The present technology practiced in Siddha and Ayurveda medicine production process is traditional cum mechanized with some modern machinery. In this enterprise, the medicine manufacturing process is undefined (i.e., intermitted in nature). The methodology of the detailed energy audit varies from industry to industry, and it is highly flexible according to the type of the industry. Here, the intermittent/interlinked traditional medicine manufacturing process is crucial to carry out the energy audit. According to the BEE guidelines, a systematic methodology for detailed energy auditing is shown in Figure 1.

The phase I: preaudit kickstarted to obtain the overall resource planning and organize the instrument for setting up a reference point for energy consumption. Here, the load curve and cost economic curves are obtained by collecting the macrolevel data from the responsible individuals and the historical dataset of the industry. The preaudit of the Siddha and Ayurvedic industry needs to be done precisely. The Indian traditional medicine manufacturing technology is unique and intermitted/noncontinuous, which cannot be altered based on the energy perspective. The lack of continuous running process machine and part loading operation is a crucial issue to address in this auditing. Therefore, planning and organizing the instruments for energy analysis and organization of resources are highly recommended.

The phase II: audit phase comprises developing the process and energy flow diagram with the active involvement of energy individuals of the industry. The survey and monitoring are carried out for all the connected loads to meet the supply and demand management of the industry. The detailed energy auditing phase is by continuous monitoring and logging of data using various energy auditing instru- ments like power on clamp meter for electrical energy studies, thermal imager for infrared thermography, and other various energy auditing instruments.

The process is followed by energy analysis using the obtained data and standard data. Based on the detailed energy audit, energy analysis is carried out. Therefore, the ENCON (Energy Conservation) opportunities proposed with the cost economics as a report to the top-level management.

The phase III: postenergy audit phase was initiated by the implementation of ENCON measures by the action plan recommended. The periodic reviews and follow-ups ensure the effectiveness of the implementation. Therefore, based on the detailed energy audit results, suggested ENCON recommendations were implemented accurately. The power quality analyzer analysis is a class " $\mathrm{A}$ " accuracy instrument used for continuous logging of electrical anomalies of the SME's power system on power quality issues like sag, swell, power factor, voltage-total harmonic distortion factor (V-THDF), and current-total harmonic distortion factor (I-THDF). The design and implementation of Intelligent Power Factor Controller (IPFC) and its effectiveness were studied in the post energy audit phase.

Also, a grid-interactive SPV power plant is designed and proposed with the power, economic, and carbon emission analysis using Solar Pro simulation software package for attaining the state of energy self-sufficiency SME. The feasibility study for the solar simulation was carried out by considering the various primary dataset of latitude, longitude, energy utilization pattern, connected load, energy demand, energy consumption details, building dimensions, type of building, and shade-free area (effective area) for solar module installation. Therefore, the proposed SPV plant is highly significant in energy self-sufficiency, and the renewable energy resource led to climate change mitigation.

The power quality analyzer (clamp-on-power meter) shown in Figure 2 is used at the vicinity of the point of common coupling (PCC) for the main power distribution panel in order to calculate the energy utilization pattern of the entire enterprise. Figure 3 shows the energy auditing carried in the enterprise. The power meter clamp is calibrated in threephase-four-wire configuration for detailed power quality and energy analysis of the enterprise. After the energy auditing analysis, the power quality issues have arrived. The graph gave the plotted results of the analysis and interpreted the same in the analysis. The power quality graphs show the total voltage, total current, power (real (kW), reactive (KVAr), and apparent $(\mathrm{kVA})$ ), power factor, voltage-total harmonic distortion factor (V-THDF), current-total harmonic distortion factor (I-THDF), and frequency.

\section{Results and Discussion of Preaudit Phase}

Energy auditing started with the collection of load curves from enterprise historical data. The load curve gives the necessary prerequests to carry out the energy auditing in the enterprise. The primary vertical axis of Figure 4 illustrates the enterprise's annual load curve, and the secondary axis gives the month-wise energy cost of the enterprise in the overall annual load curve. This load and cost curve reveals 


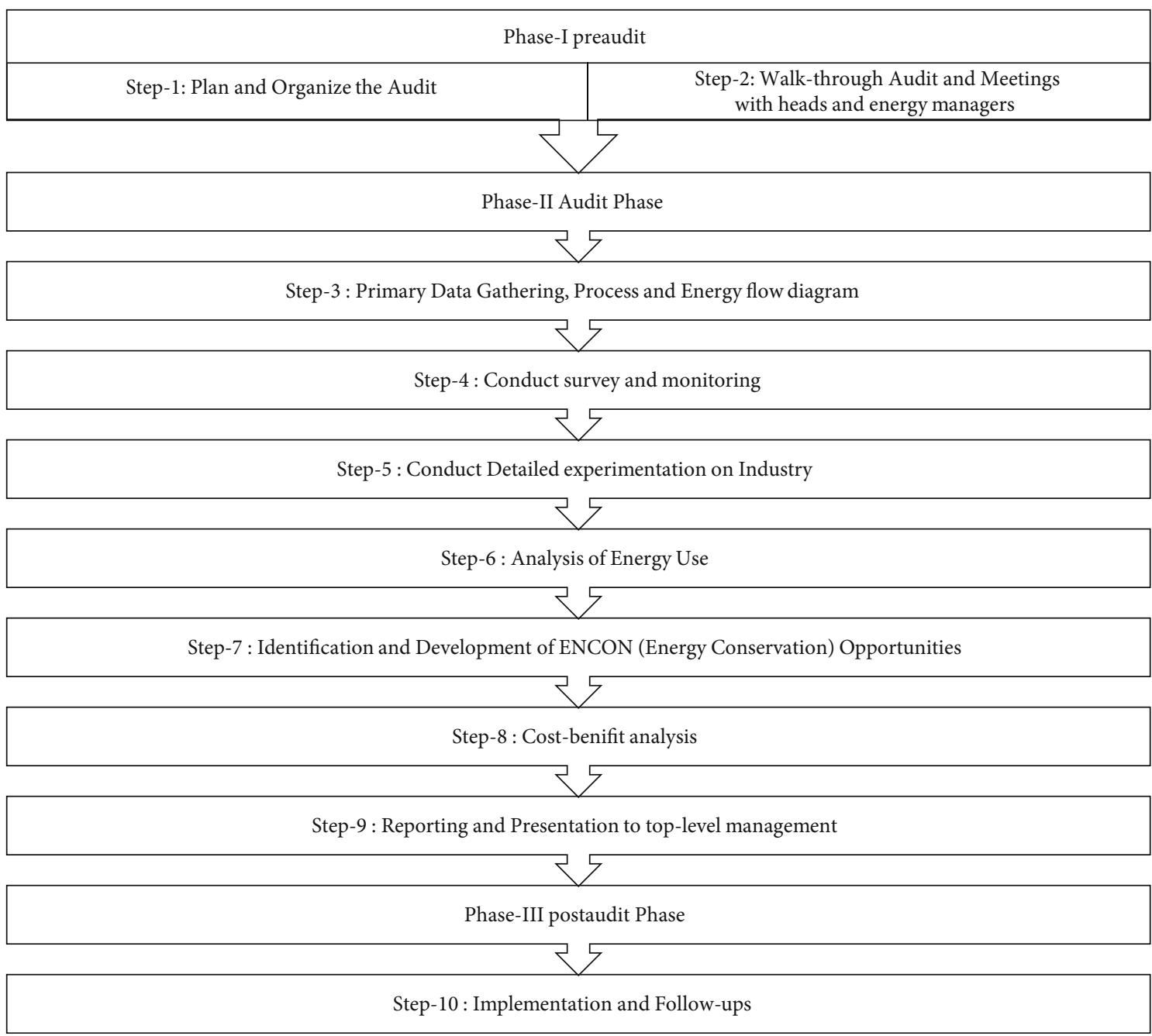

Figure 1: Systematic detailed energy auditing methodology.

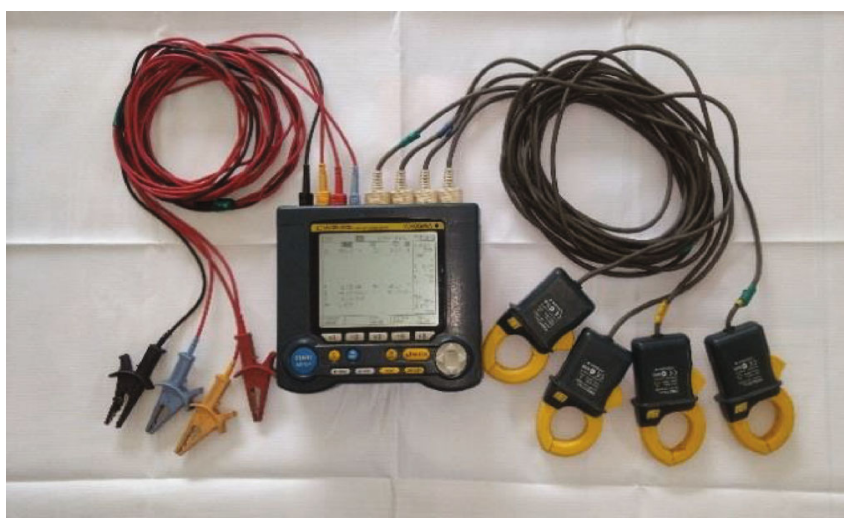

Figure 2: Power on clamp meter for energy auditing.

the preaudit phase of an energy audit by revealing a power consumption pattern. The overall electrical energy consumption concerning time gives the industry's loading pattern for a particular time.

\section{Results and Discussion of Audit Phase}

Figure 5 shows the gives of time versus voltage performance of the enterprise. The analysis starts from the beginning of the load to the load's termination to study the starting spikes or surges in the power system by connecting the power on clamp meters on the PCC. From the voltage profile, it is inferred that the presence of voltage unbalances in the system. The $5 \%$ voltage unbalance will increase the current consumption by 1 to 6 times of rated current consumption and reduce the efficiency of the electric motor load in the power system.

Figure 6 shows the graphical representation of the time versus the current profile of the enterprise. The phase-wise current consumption is R-phase (A), Y-phase (A), B-phase (A), and neutral (N), respectively. Here, nearly $30 \mathrm{~A}$ of neutral current is present in the unit, and the total current is about $35 \mathrm{~A}$ during the recording period. The presence of unbalance in the current consumption profile clearly defines the poor load sharing between each phase. The unbalanced loads and the presence of current harmonics lead to a high neutral current in the system. 


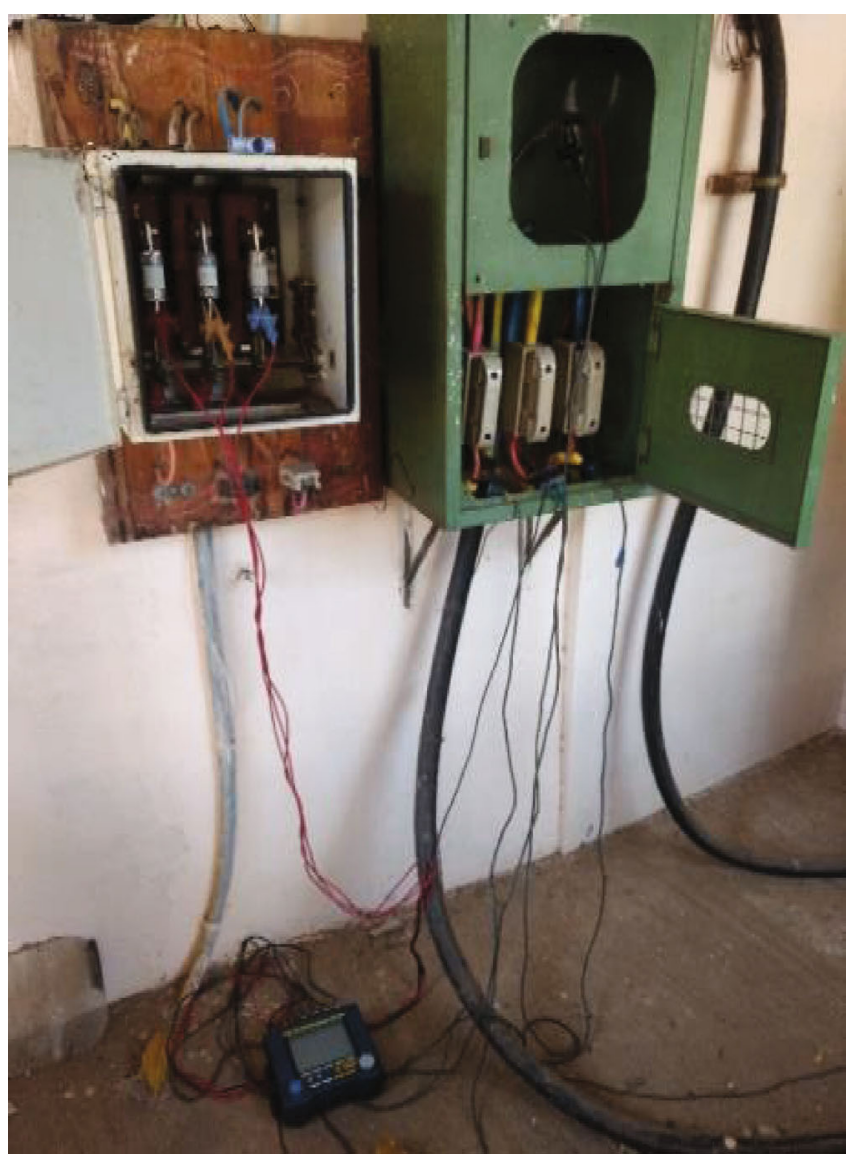

FIGURE 3: Energy auditing at point of common coupling.

Figure 7 shows the time versus real (W), reactive (VAr), and apparent power (VA). The presence of apparent power is more in the unit. The significance of reactive power injection in the SME is a minimum value, which concludes the consequence of the enormous consumption of the real power since there is a prevalence of lagging power factor in the enterprise. The need for compensation is essential to equate the power consumption without a considerable amount of wastage.

Figure 8 shows the graphical representation of time versus $\%$ voltage-total harmonic distortion factor (V-THDF) from the graphical representation; the Y-phase voltage THDF is higher than other phases. At the PCC, the maximum allowable V-THDF is of 5\% as per the IEEE 519-2014 and IEC 61000 standards. This voltage harmonic distortion in the enterprise is under the Central Electricity Authority (CEA) regulations. The presence of poor V-THDF directly reflects the temperature rise of the electric motor load in the enterprise. As the temperature increases, the efficiency of the motor drastically decreases.

Figure 9 shows the time versus current-total harmonic distortion factor (I-THDF). At the PCC, the maximum allowable I-THDF if of $8 \%$ as per the IEEE 519-2014 and IEC 61000 standards. The presence of harmonics in the Yphase has higher value compared that with the other phase harmonics. The overall harmonic level of the enterprise is exceeding the central electricity authority rules and regulations.
Figure 10 gives a graphical representation of the time versus the power factor of the enterprise. The range of power factor varies from 0.65 to 0.8 without any compensation technologies. The inefficient, ancient, and rewinding induction electric motor loads are the primary sources for producing low power factor. Figure 11 gives the graphical representation of the time versus frequency of the enterprise. There is no significant variation of frequency. Therefore, skin effect is minimum in the SME.

The enterprise has low power quality indices like lagging power factor, voltage, and current harmonic distortion, which unbalance from the detailed energy audit analysis. Therefore, the harmonic mitigating filter circuit is highly recommended, and proper load balancing between the phases is essential for better power quality. Also, the power factor improvement capacitors will address the above-mentioned power quality issues by the compensation technique.

From the detailed energy auditing, it is perceived that there is an unbalance exists in phases [30]. The loads are not evenly distributed in the system, and several loads are critical, which generates positive, negative, and zero sequence errors. Frequency variations are high due to nonlinear loading examples like Hammer Machine, Ball Mill. The power factor for the motors is about 0.65 . Total harmonic distortion factor (THDF) is higher in the Y-phase, which recorded as $14 \%$, which is above IEEE standard limits of V-THDF of $5 \%$ and I-THDF [31] of $8 \%$ at point of common coupling (PCC) as per the norms of Central Electricity Authority (CEA).

There are steps to study the sequence of operation of a particular medicine manufacturing process to get rid of the harmonic prone environment. The electrical operation is scheduled accordingly to the phase balancing with careful consideration of critical and nonlinear loads without affecting their traditional operations during the production process. This will reduce the neutral current and enhance the overall power quality of the enterprise.

5.1. Condenser Calculation of Intelligent Power Factor Controller (IPFC). The required leading KVAr compensation by P.F. correction equipment [32]

$$
\mathrm{KVAr}=\mathrm{kW}(\tan \varnothing 1-\tan \varnothing 2) \text {. }
$$

The sum of the machine's horse power rating is the active power for the power factor improvement calculation from 0.65 to 0.99 .

Total active power $=($ sum of all connected HP $) * 746$,

$$
\begin{gathered}
\text { Total active power }=(94 * 0.746)=70.124 \mathrm{~kW}, \\
\operatorname{KVAr}=70.124(\tan 49.46-\tan 8.11) .
\end{gathered}
$$

The leading reactive power (KVAr) was supplied by power factor correction equipment $=72,052.41 \mathrm{KVAr}$.

The KVAr compensator rating of $72,052.41$ is sufficient to enhance the power factor. 


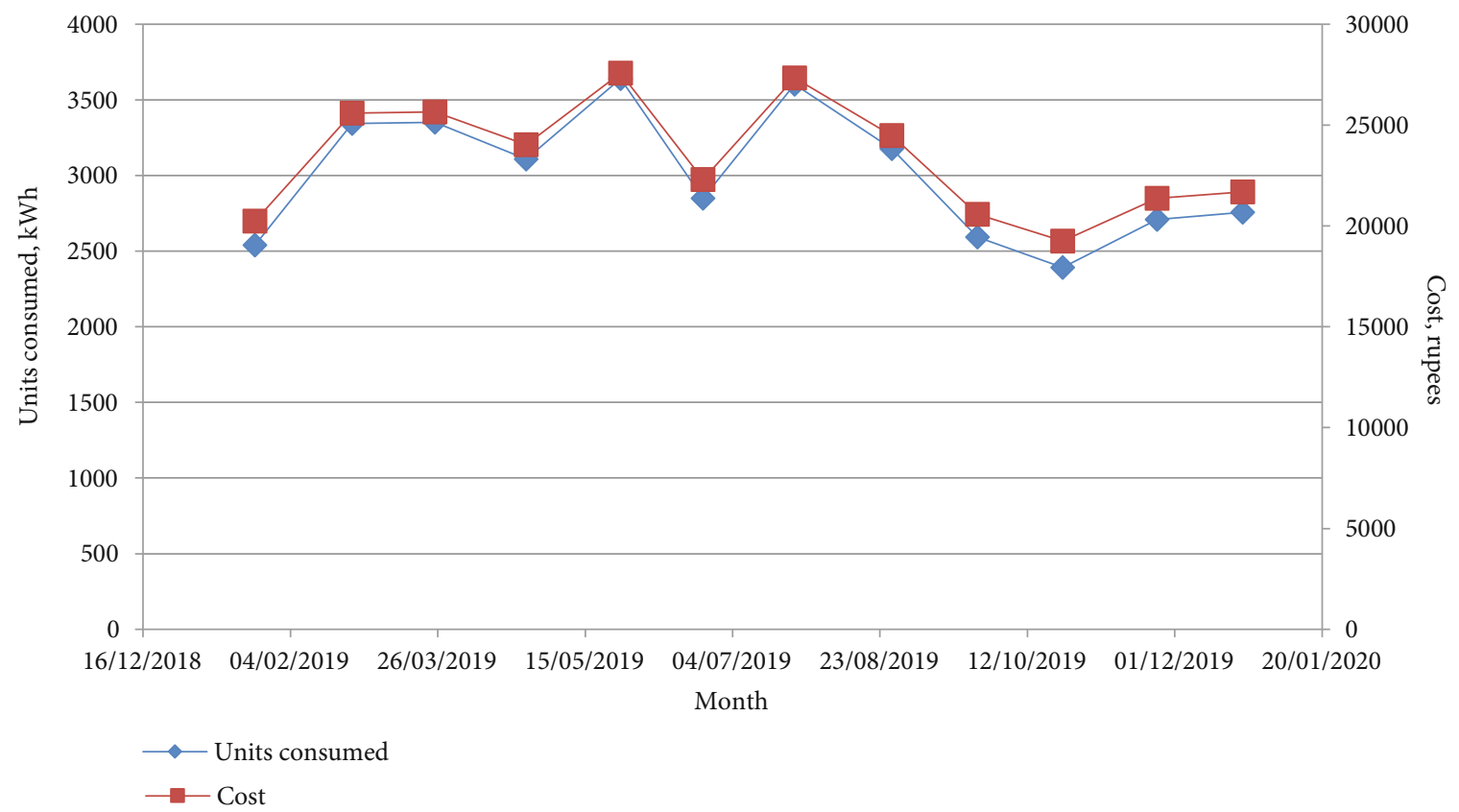

FIgURE 4: Load and cost economics curve of SME (phase I-preaudit).

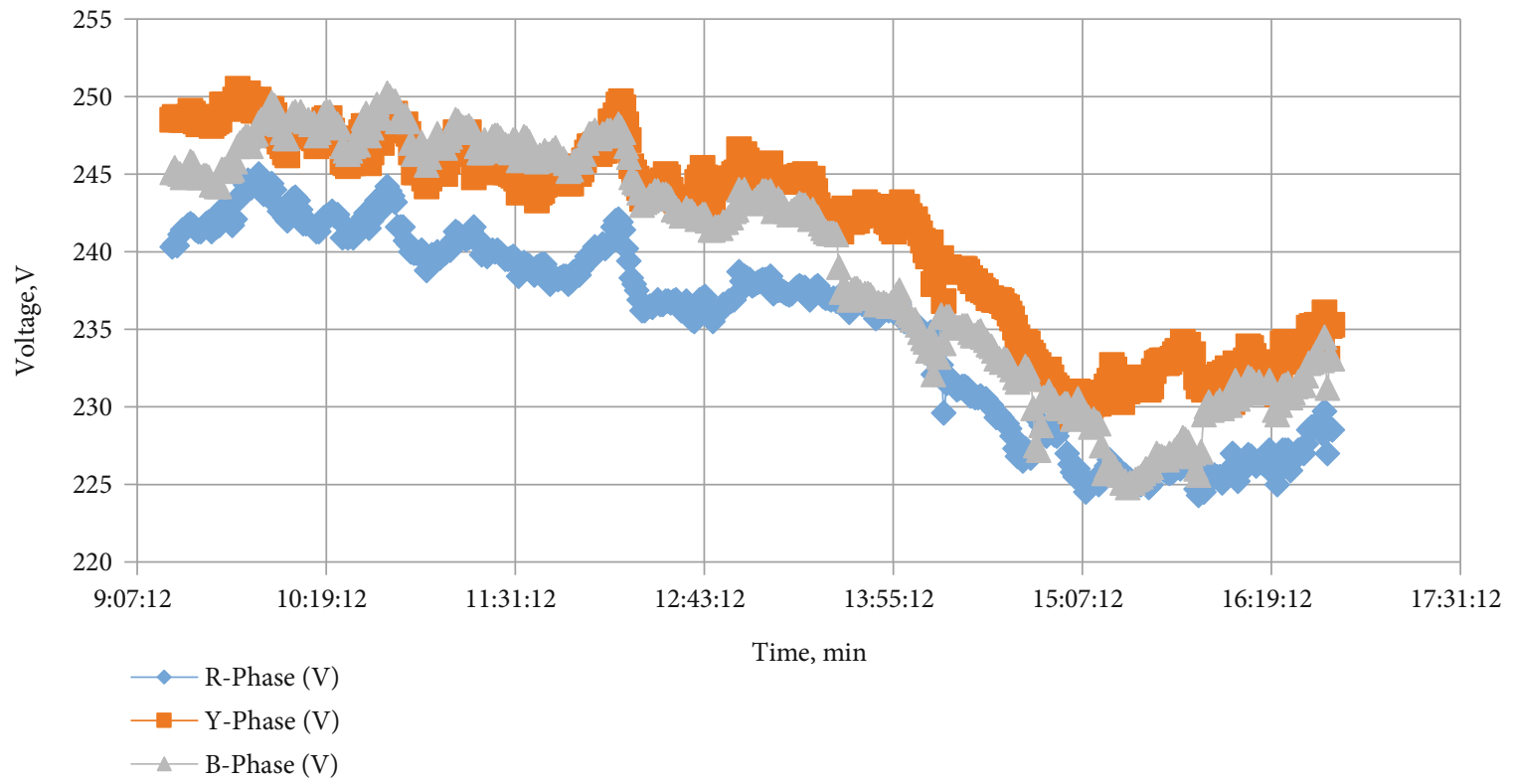

Figure 5: Time vs. voltage (phase II-audit phase).

5.2. Intelligent Controller. Figure 12 shows the Intelligent Power Factor Controller (IPFC), a smart, simple, accurate [33], and robust reactive power compensator. It is versatile in power factor mitigation [34] by its smart features of load sensing and storage of historical datasets. The IPFC is powered by various combinations of power capacitors for reactive power compensation [32]. The AT89S52 [35] is low power consuming, high-performance 8-bit Microcontroller with $8 \mathrm{k}$ bit in-system programmable flash memory.
It provides the following standard features: 32 input-output lines, 256 bytes of RAM, watchdog times, two data pointers, fully duplex serial port, clock circuit, and memory storage facility. The voltage and current transformers are used to sense and measure the system's input voltage and current. The zero-crossing filter is used to obtain the instantaneous voltage and current point at which there is no voltage and current, respectively. The IPFC is equipped with the data storage facility for logging of present load and historical 


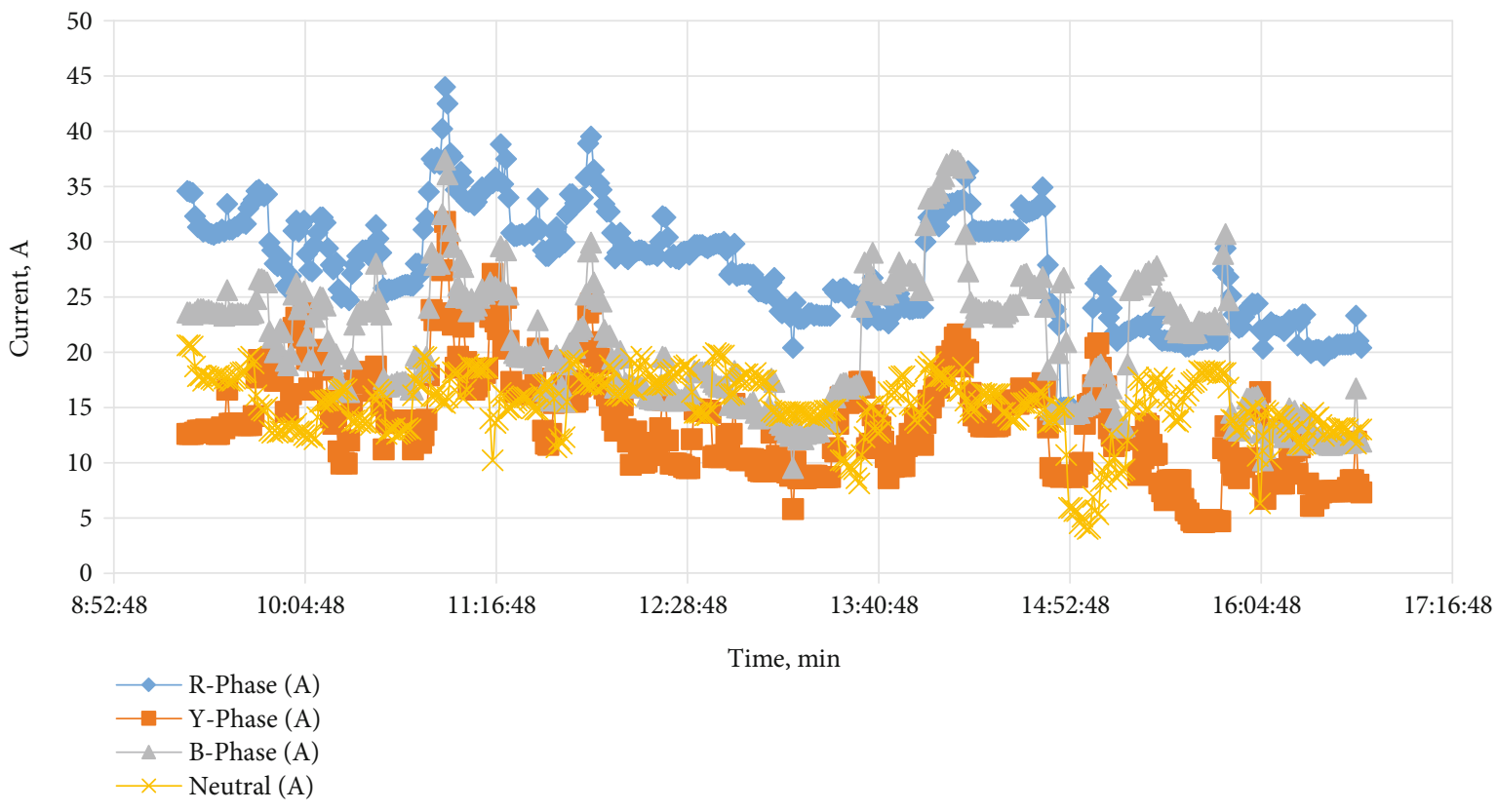

Figure 6: Time vs. current (phase II—audit phase).

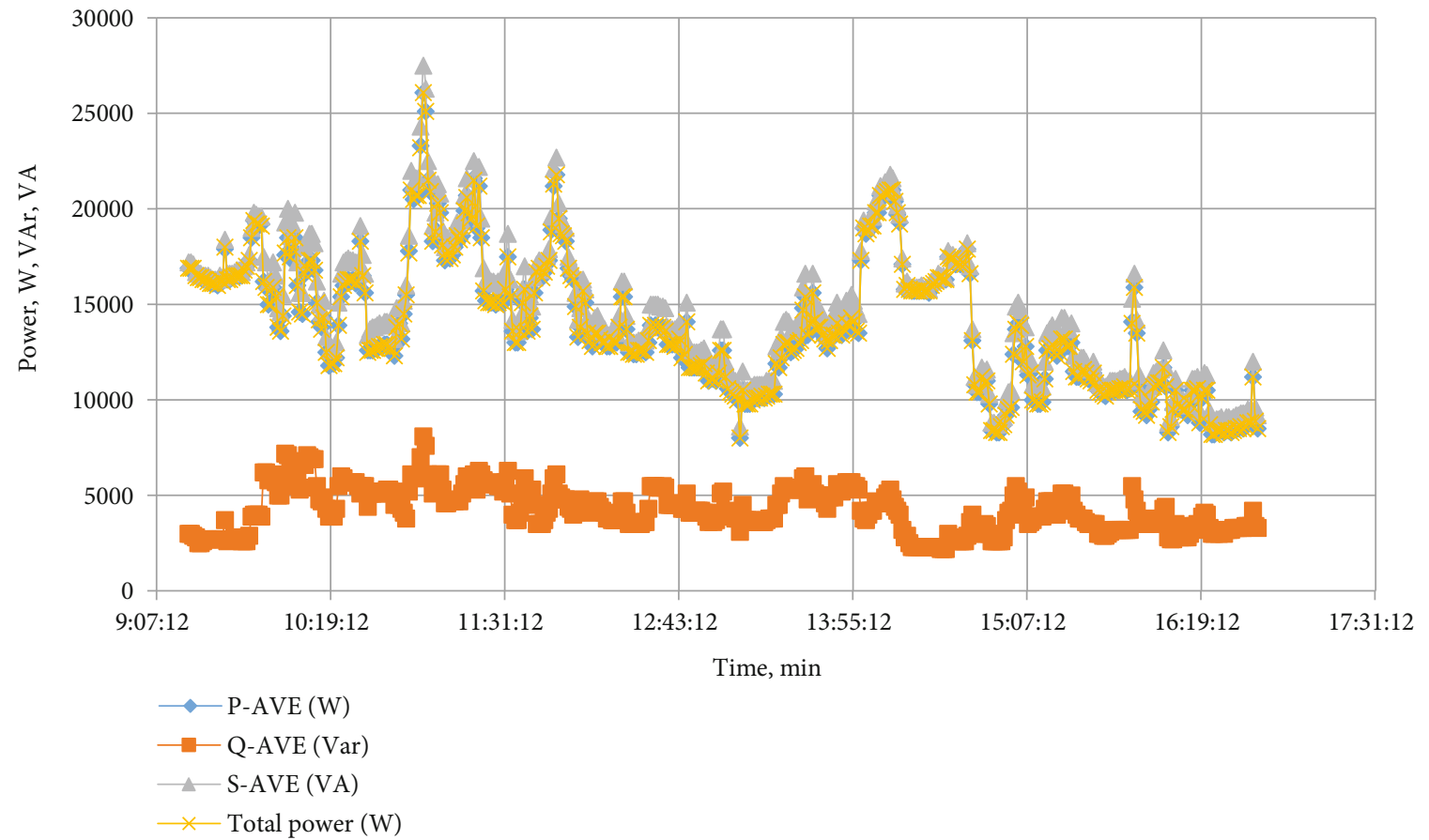

Figure 7: Time vs. power (phase II—audit phase).

datasets for better reliable and faster compensation. The relay circuit is to electrically make (turn on) and break (turn off) the shunt capacitors [36] from the system. Based on the controller's load-sensing signal, the switching on and off of shunt capacitors is carried out. The relay drive is powered by the embedded system [37] to reduce the overall system cost to have robust, accurate control, and cost-effective.

\section{Results and Discussion of Postaudit Phase}

The postaudit phase is carried out to calculate the effectiveness of the installed IPFC unit. Figure 13 gives the graphical representation of the time versus voltage profile of SME after improvement using IPFC installation. The IPFC unit's installation achieves a $5 \%$ increase in the voltage profile. Figure 14 


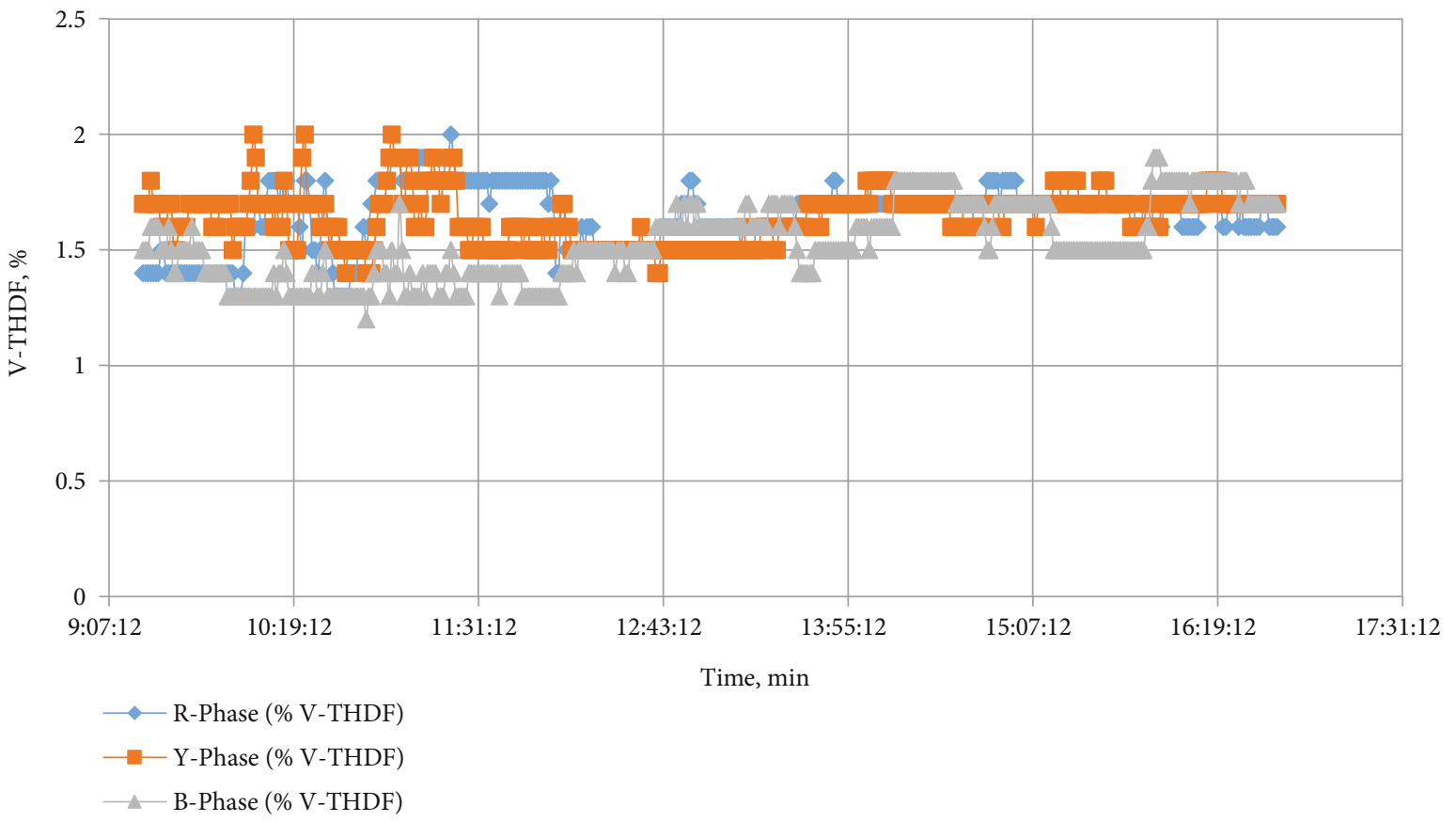

Figure 8: Time vs. V-THDF (phase II-audit phase).

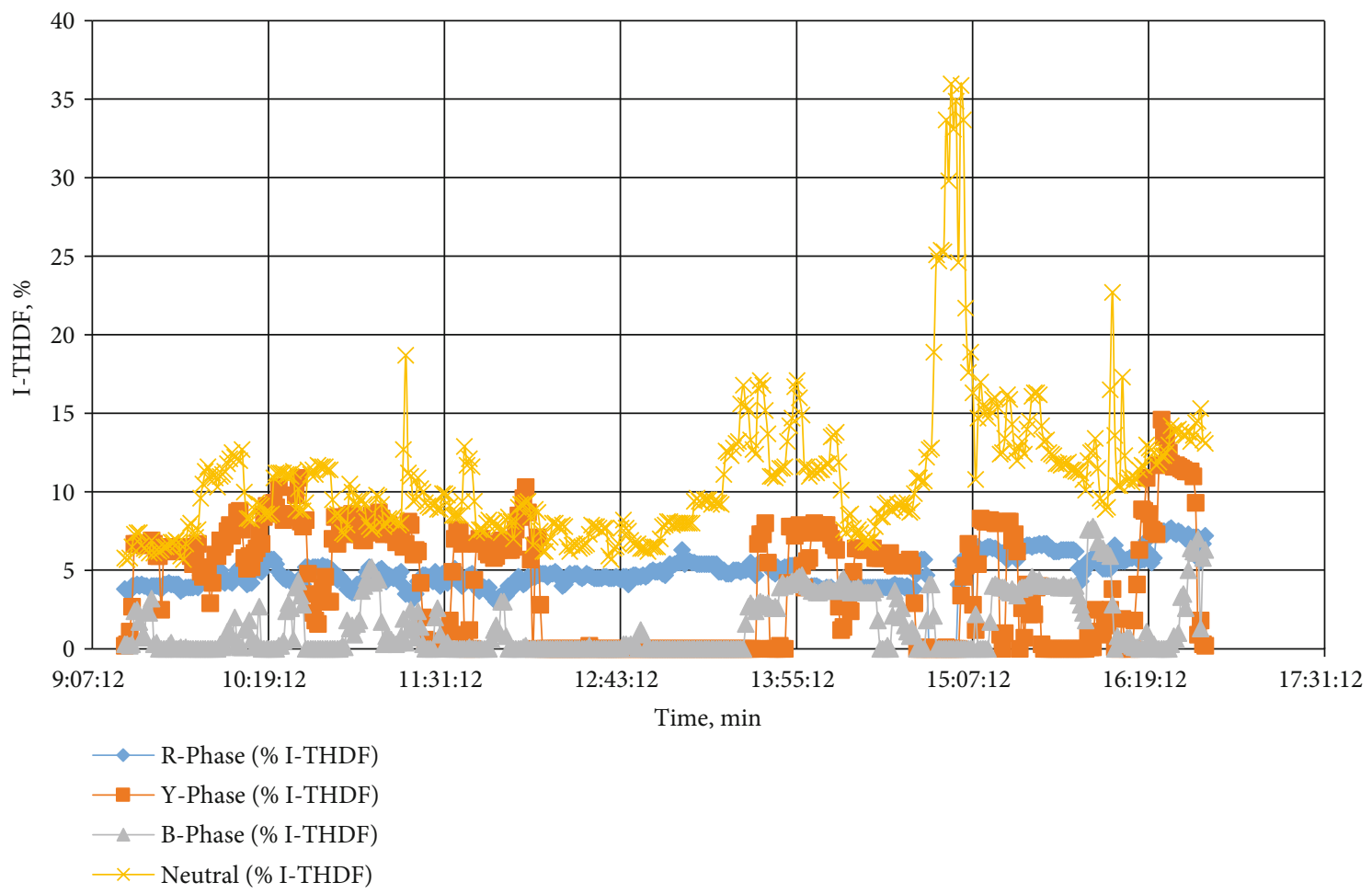

Figure 9: Time vs. I-THDF (phase II—audit phase).

illustrates the postaudit time versus the current profile of the SME. The installation of the IPFC unit achieves a $33.33 \%$ reduction in the current consumption profile.
Figure 15 illustrates the graphical representation of time versus power includes active (or) real, reactive, apparent, and total SME power profile. The $28.88 \%$ reduction of total 


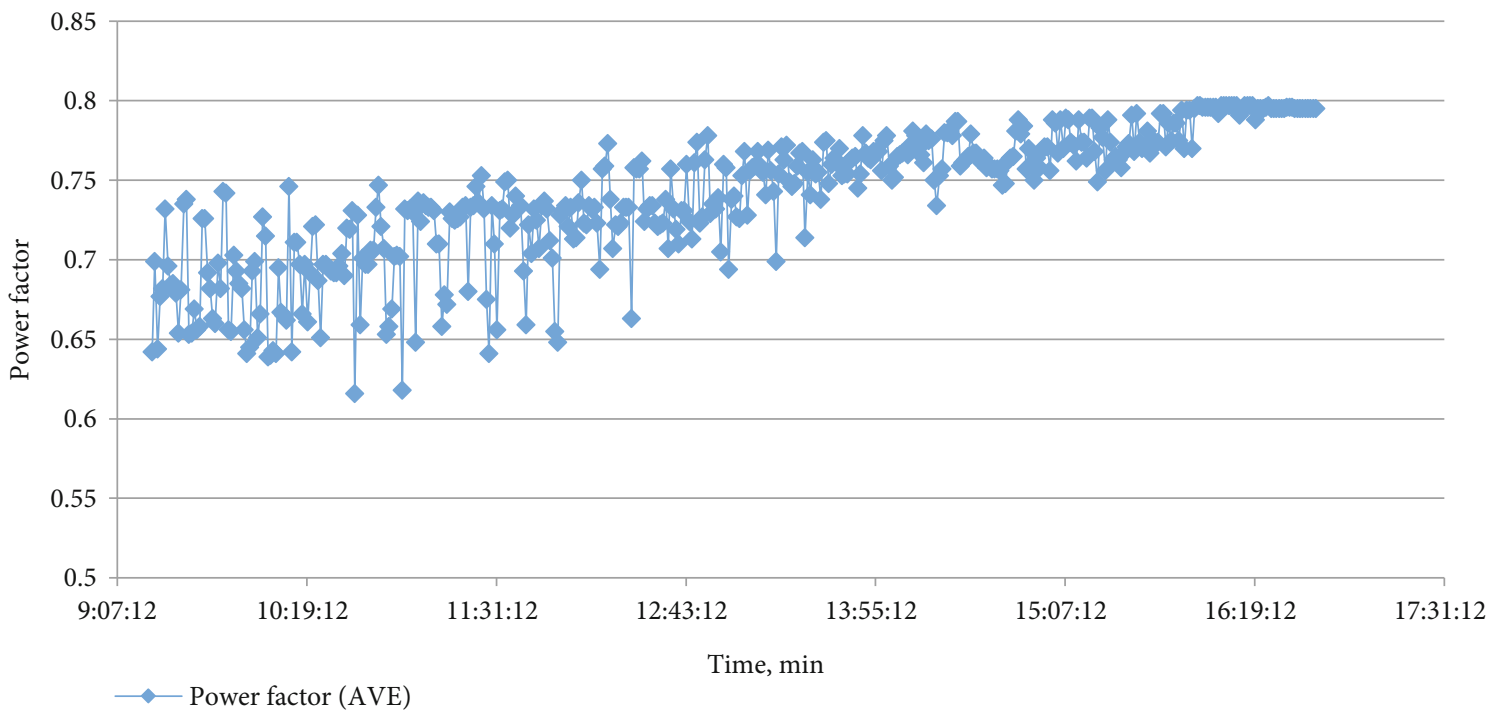

FIgURE 10: Time vs. power factor (phase II—audit phase).

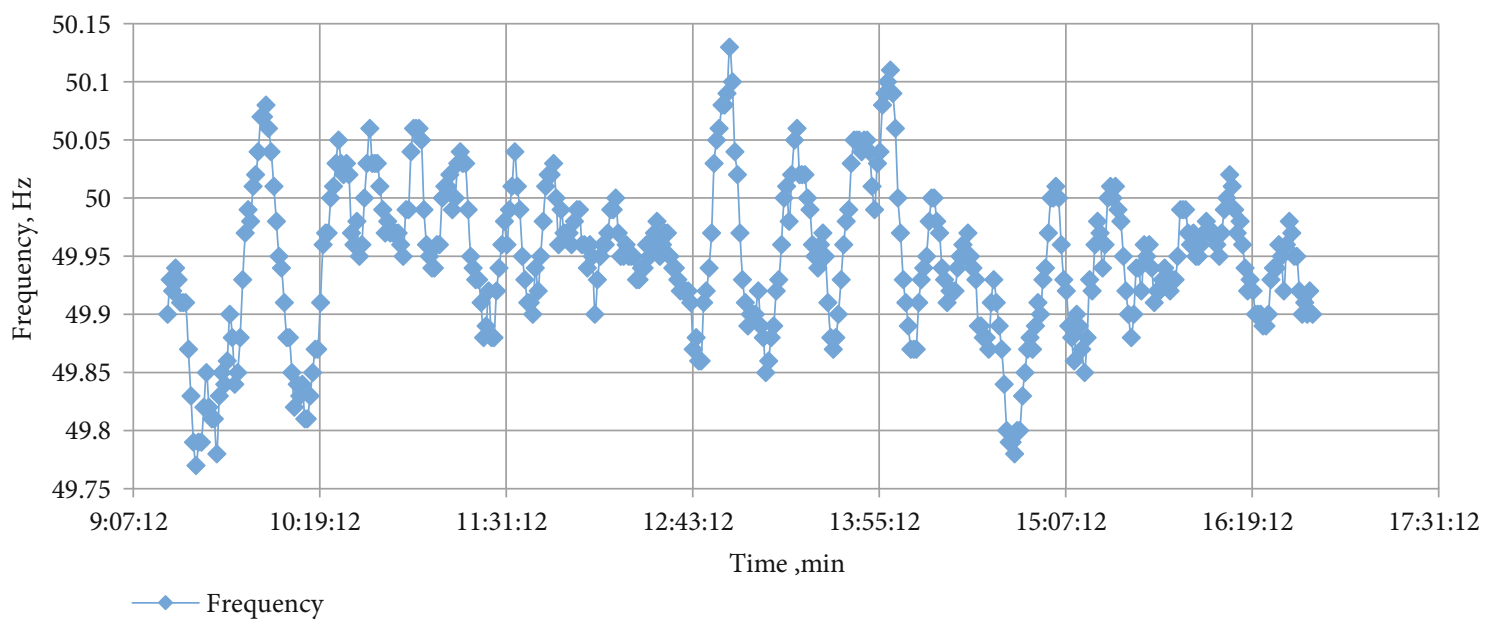

FIGURE 11: Time vs. frequency (phase II-audit phase).

power is achieved by installing the IPFC unit in the SME. Figure 16 gives the graphical representation of time versus the overall power factor of the SME at the point of common coupling after the installation of the IPFC unit. The 65\% increase in the overall power factor is achieved after installing the IPFC unit in the SME. Figure 17 gives the time versus total voltage harmonic distortion factor after the installation of the IPFC unit. The V-THDF of $1.6 \%$ is within the IEEE 519 standards and limits under central electricity authority guidelines. Figure 18 gives the time versus total current harmonic distortion factor after the installation of the IPFC unit. The I-THDF of $4.8 \%$ is within the IEEE 519 standards and limits under central electricity authority guidelines. Also, the $27.27 \%$ reduction is achieved in the neutral I-THDF after installing the IPFC unit. Figure 19 gives the graphical representation of the time versus frequency profile that ensures the less amount of skin effect after installing the IPFC unit.
Figure 20 gives the graphical representation of the exact comparison of power factor before and after installing power factor improvement capacitors (Intelligent Power Factor Controller). The average increase of lagging power factor from 0.6 to 0.99 , with the IPFC controller's installation, is ascertained and shown in Figure 20. The 65\% increase in the lagging power factor is achieved after the installation of the IPFC.

6.1. Climate Change Mitigations through Power Factor Improvement. According to the Energy Information Administration (EIA), the USA, the electricity utilization holds $37 \%$ of carbon emission in the overall greenhouse gas emission. As per the CEA of India [38], $1 \mathrm{kWh}$ of electricity emits $2 \mathrm{~kg}$ of $\mathrm{CO}_{2}$. From the detailed energy audit, we came to know the amount of $\mathrm{CO}_{2}$ emitted from the enterprise operation. 


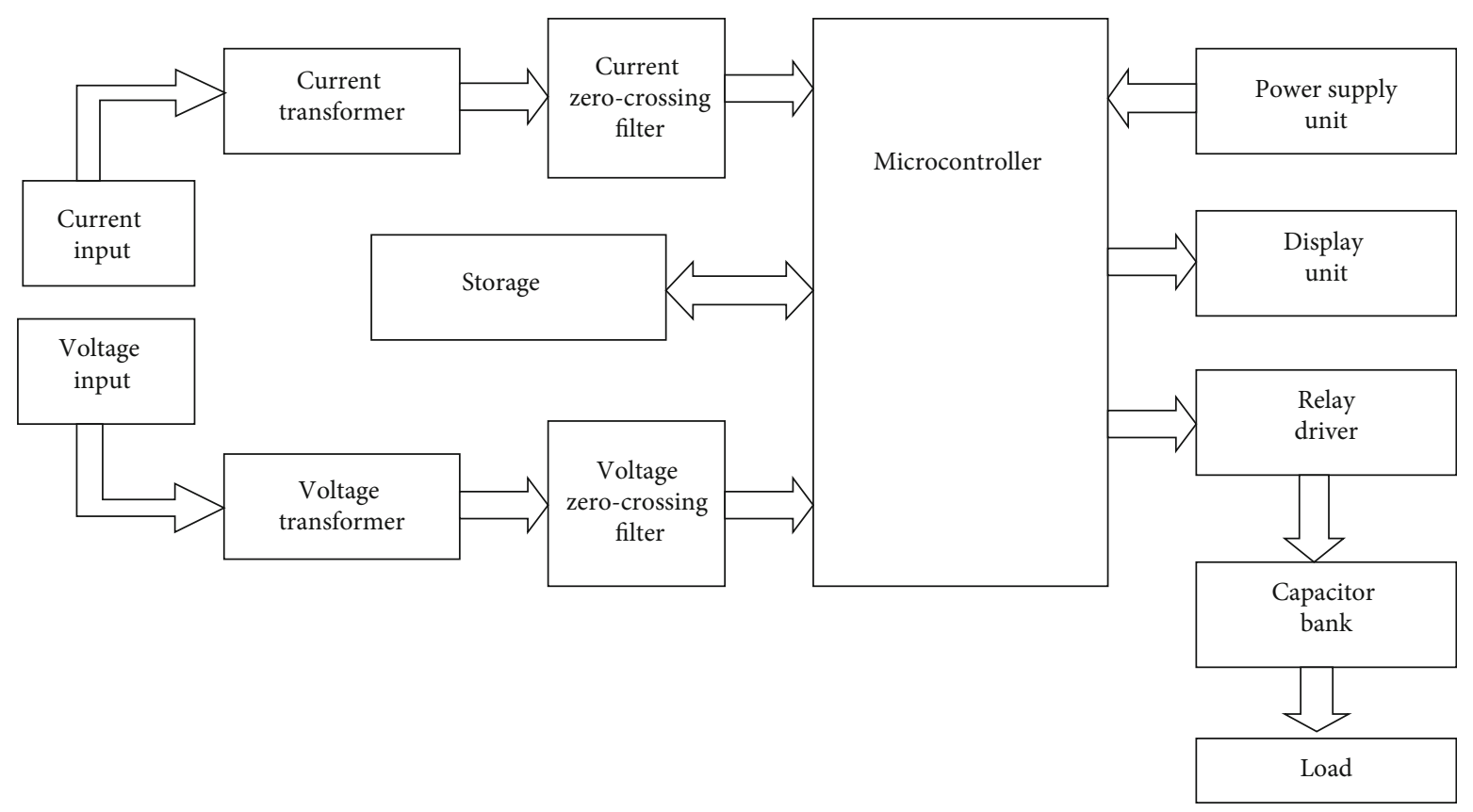

FIGURE 12: Block diagram of the designed intelligent controller.

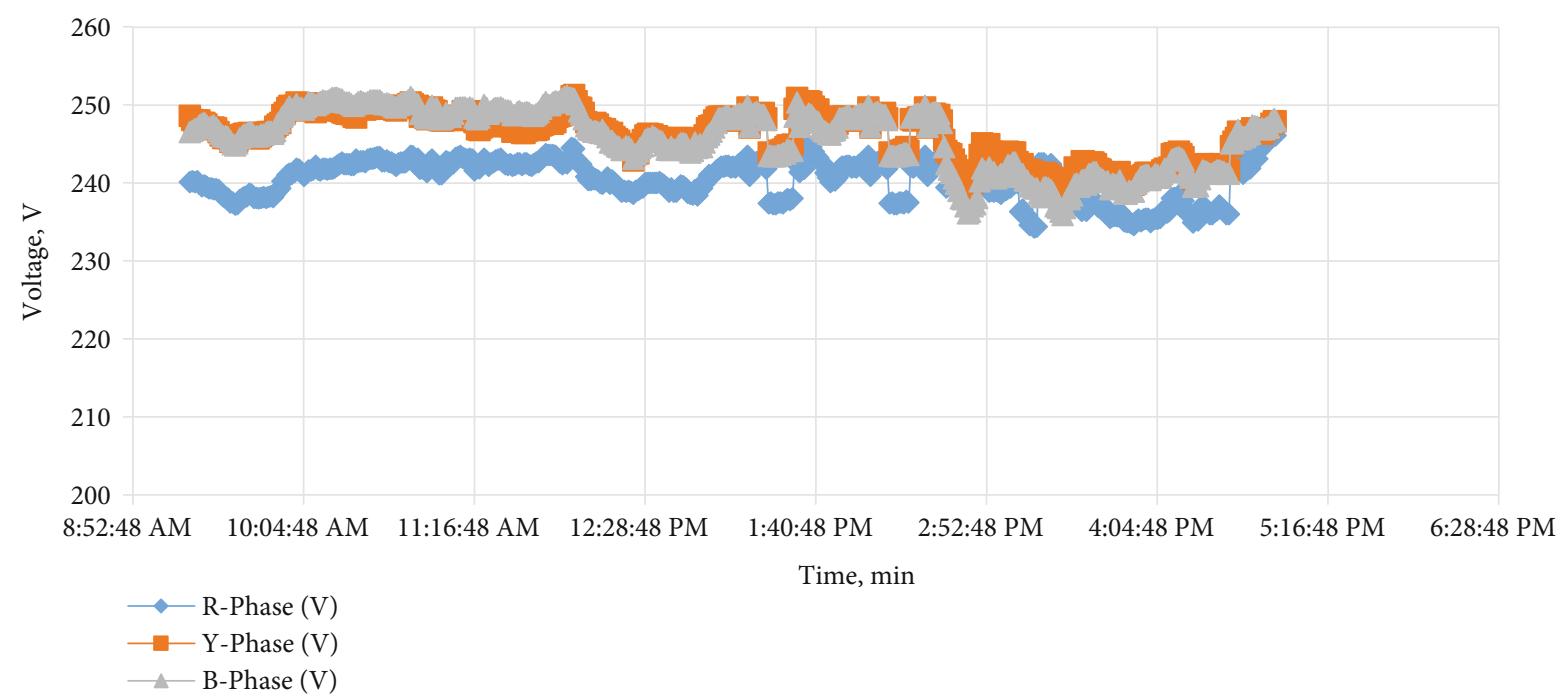

FIGURE 13: Time vs. voltage (phase III-postaudit).

\subsubsection{Before Power Factor Improvement.}

$\mathrm{CO} 2$ emission $=($ power in $\mathrm{kWh} /$ day $) * 2 \mathrm{~kg}$ of $\mathrm{CO}_{2}$.

The per-day power consumption is of $208 \mathrm{kWh}$ before improvement; therefore, the following carbon dioxide emissions are calculated as follows:

\subsection{2. $\mathrm{CO}_{2}$ Reduction after Power Factor Improvement.}

$\mathrm{CO} 2$ emission $=($ power in $\mathrm{kWh} /$ day $) * 2 \mathrm{~kg}$ of $\mathrm{CO}_{2}$

The per-day power consumption is of $205.92 \mathrm{kWh}$ before improvement; therefore, the following carbon dioxide emissions are calculated as follows:

$$
\mathrm{CO} 2 \text { emission }=411.5 \mathrm{~kg} \text { of } \mathrm{CO}_{2} \text { per day }
$$




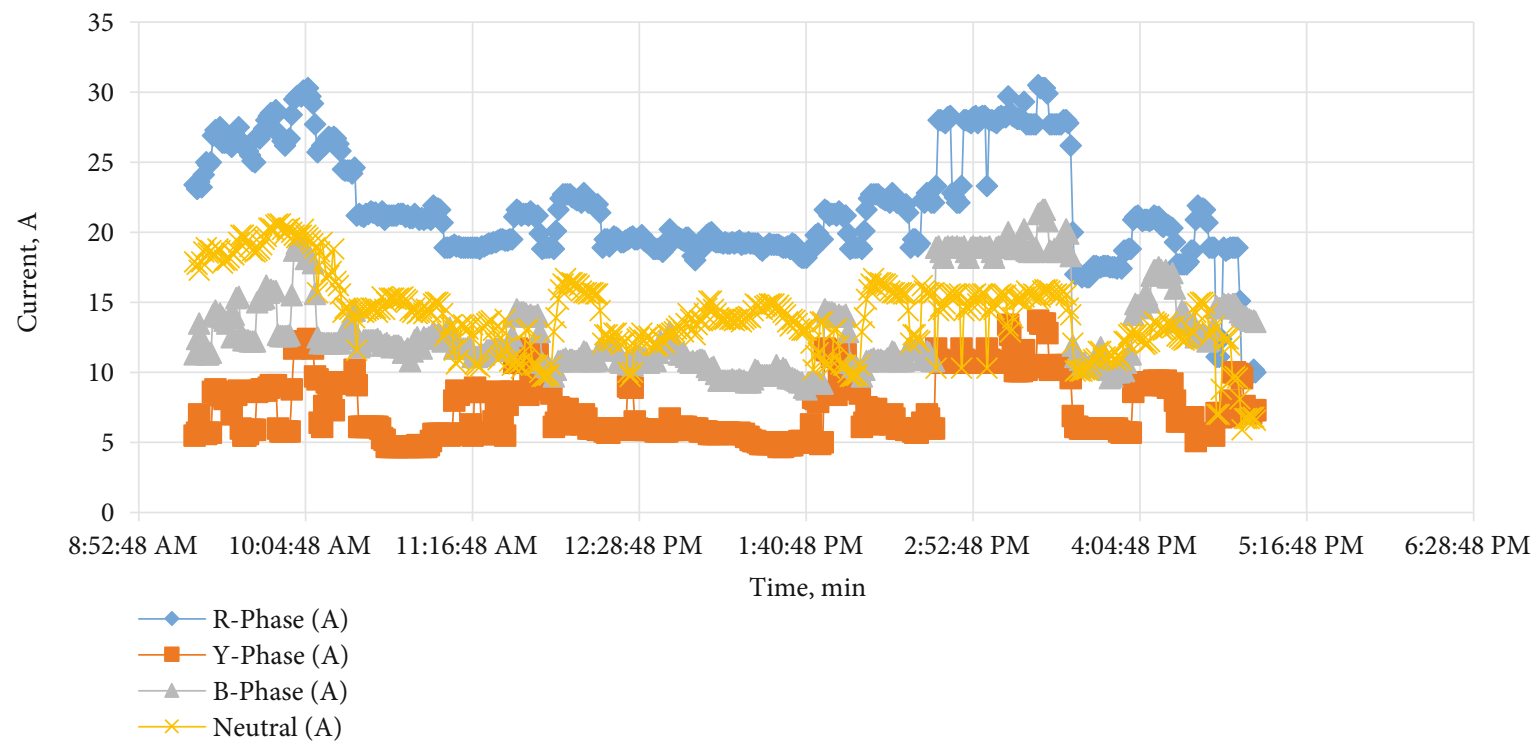

FIGURE 14: Time vs. current (phase III-postaudit).

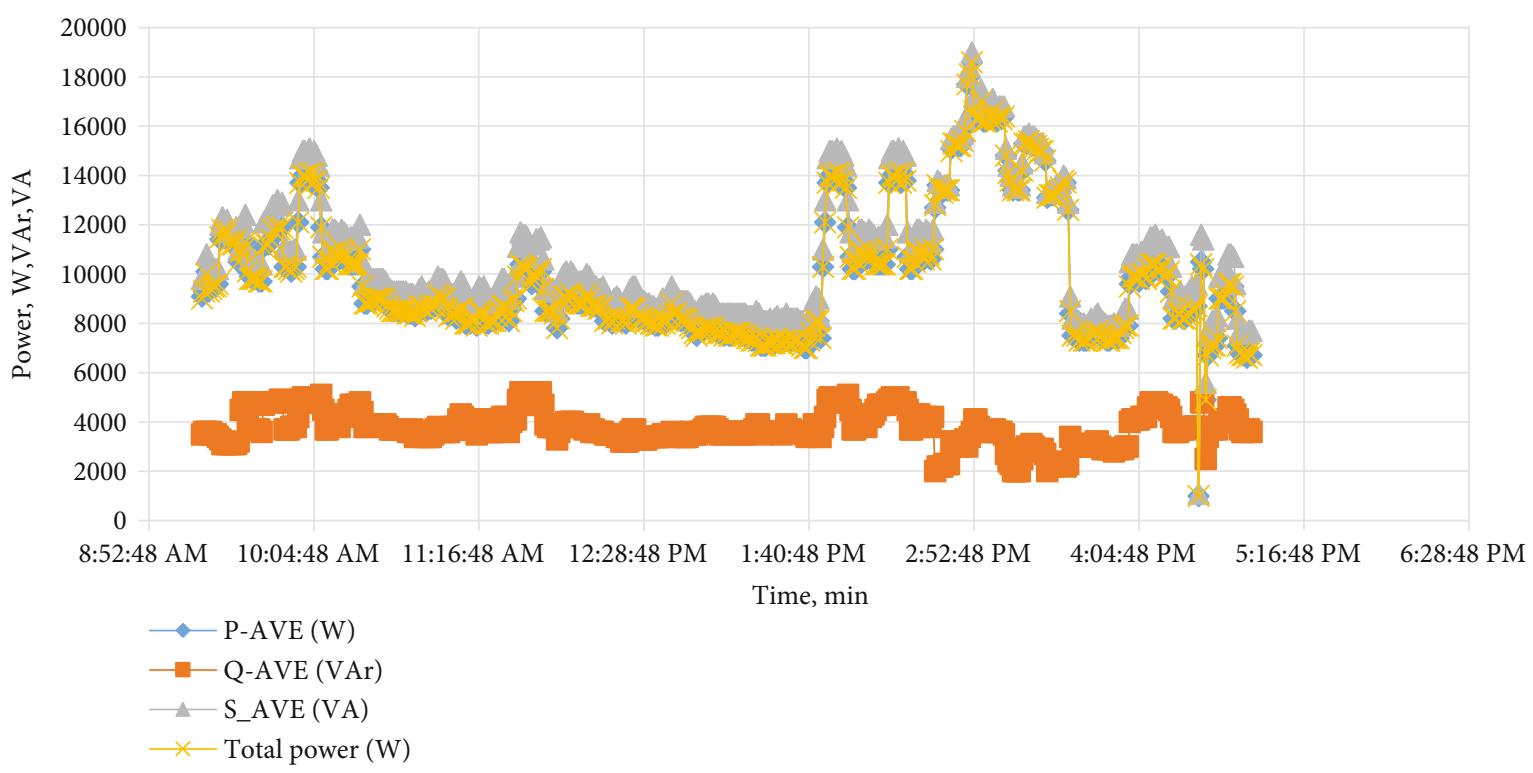

FIGURE 15: Time vs. power (phase III-postaudit).

Therefore, per day saving is $4.5 \mathrm{~kg}$ of $\mathrm{CO}_{2}$.

$$
\text { Per year saving of } \mathrm{CO}_{2}=1296 \mathrm{~kg} \text { of } \mathrm{CO}_{2} \text {. }
$$

\section{Design of Proposed Grid-Interactive Solar Photovoltaic System}

Based on the detailed energy audit of the SME, the gridinteractive photovoltaic system is proposed for climate change mitigation and designed by the Solar Pro v4.5 (Photovoltaic System simulation software). As per norms of Central Electricity Authority (CEA) and Tamil Nadu Electricity Regulatory Commission (TNERC), 100\% of the sanctioned demand [39] can be taken as the capacity of a grid-connected solar photovoltaic rooftop system. Also, the overall energy self-sufficiency is ensured via SPV installation sustainably.

Figure 21 gives the overall single line diagram of the proposed $100 \mathrm{kWp}$ solar photovoltaic power plant created using the PVsyst software. The general construction of the plant is divided into three prominent cases as PV array side (includes PV array and diodes), system side (includes inverter and its energy out), and load side (includes load, energy used, energy over, and energy back-up) for ease of operation and maintenance purposes. A $360 \mathrm{Wp}$ polycrystalline module powers the $100 \mathrm{kWp}$ SPV plant with a compactable string inverter for better grid interaction. 


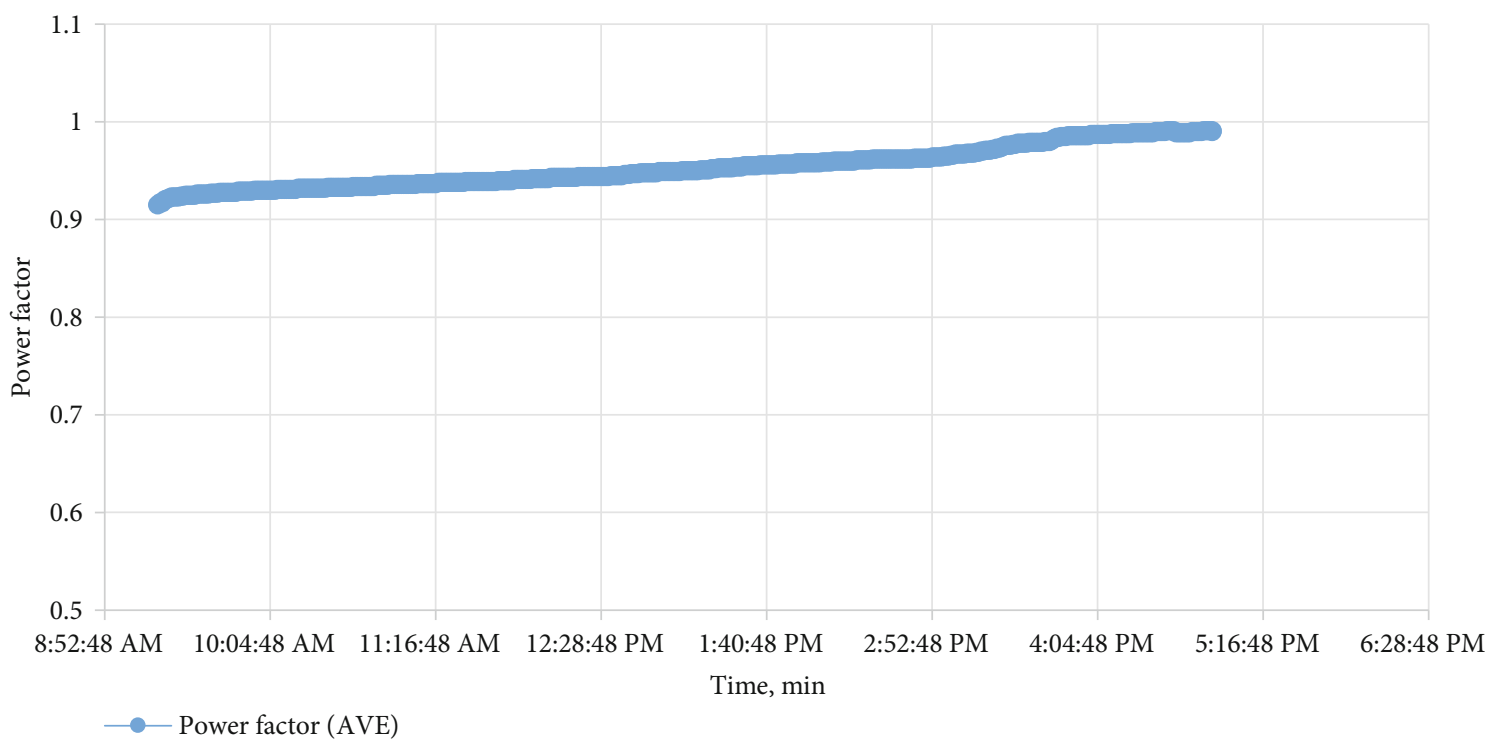

FIgURE 16: Time vs. power factor (phase III-postaudit).

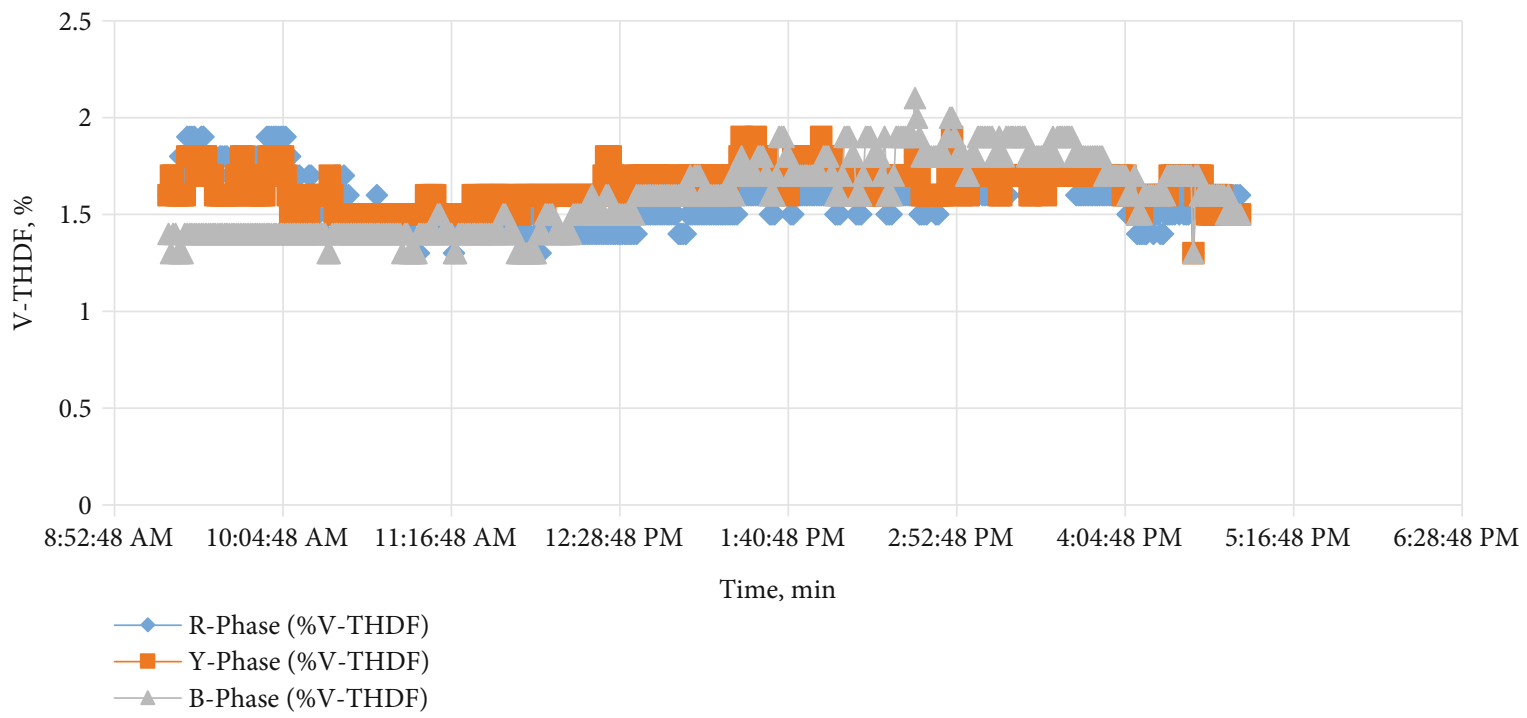

Figure 17: Time vs. V-THDF (phase III-postaudit).

Figure 22 gives the 3D CAD simulation of the proposed $100 \mathrm{kWp}$ SPV plant. The interactive 3D CAD of Solar Pro software aids in developing the virtual design of $100 \mathrm{kWp}$ SPV plant in the SME enterprise, which creates better performance optimization like shading and space distribution of SPV module installation in the premises of the enterprise.

The space optimization of the SPV plant is carried out by 3D CAD simulation of the proposed plant. The module-level dimension specifications are given as input, and optimal string and array combinations arrive by considering the inverter specification's capacity. The real-time two primary criteria are weight distribution for load-bearing capacity of the building and space availability for demand and installed capacity match. The ample space is available in the SME for the installation of the SPV plant. Therefore, space optimization is carried out by choosing the weight distribution for load-bearing capacity in the building. According to the guidelines, space and weight distribution are precisely taken as $30 \mathrm{~kg} / \mathrm{m}^{2}$ to $60 \mathrm{~kg} / \mathrm{m}^{2}$ of weight distribution throughout the SPV plant's installation, including module and module mounting structure.

Figure 23 illustrates the solar irradiation details like total, horizontal, and direct irradiation of the enterprise generated by Solar Pro design software. The metrological data of Solar Pro simulation software is developed with the accurate metrological dataset from the NADO (New Energy and Industrial Technology Development Organization), a Japanese weather association. The collection of 1600 location dataset is equipped with the Solar Pro software. Here, the month of March is significantly having the maximum recorded irradiation of $220 \mathrm{kWh} / \mathrm{m}^{2}$ with the maximum generation potential. 


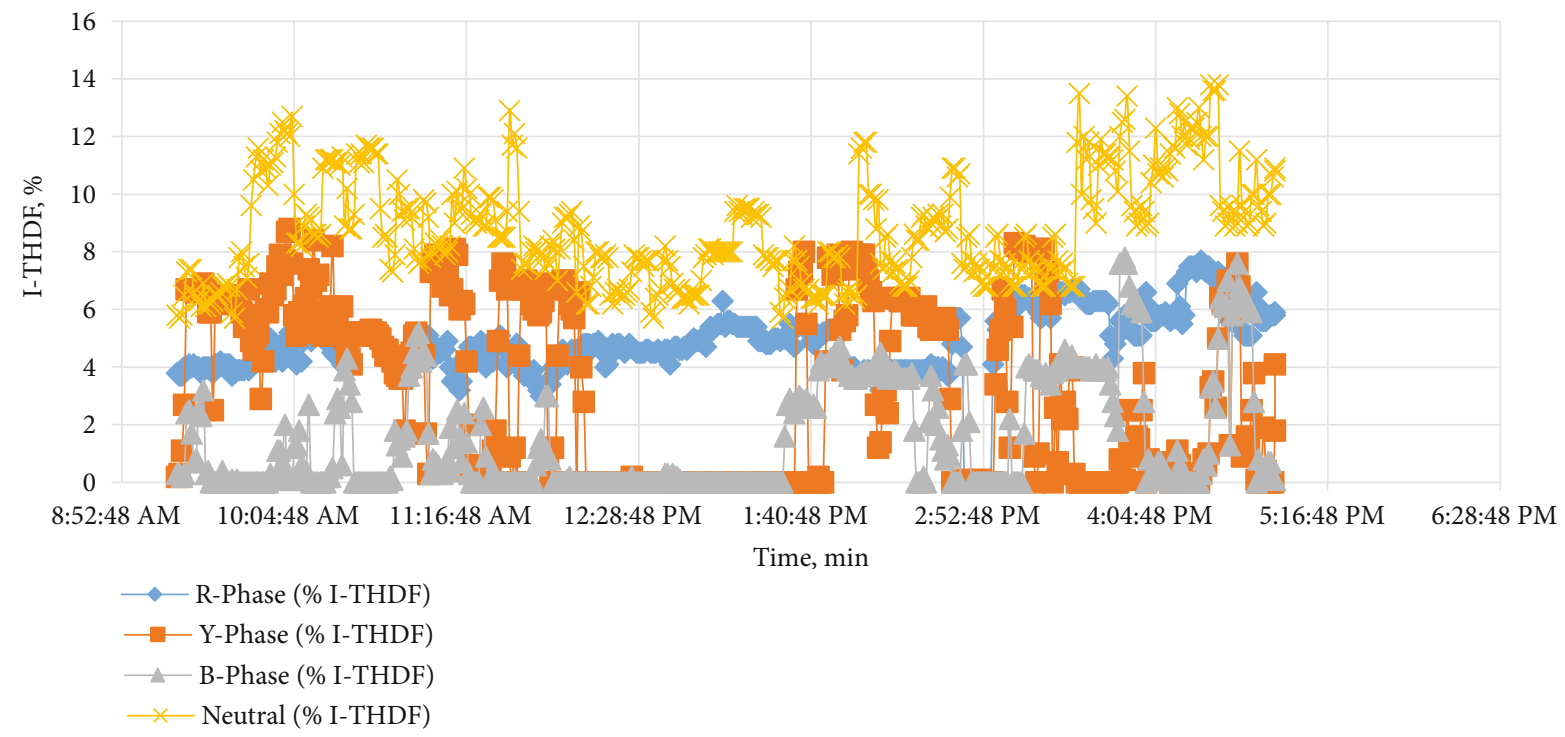

Figure 18: Time vs. I-THDF (phase III-postaudit).

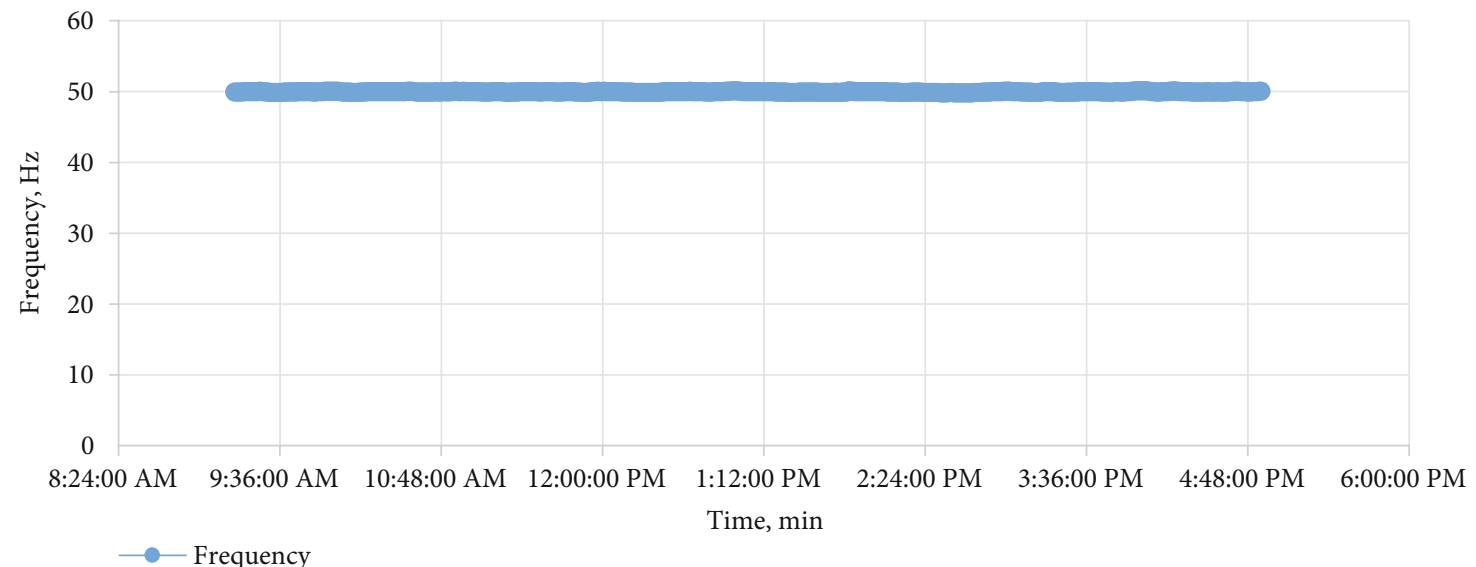

FIGURE 19: Time vs. frequency (phase III-postaudit).

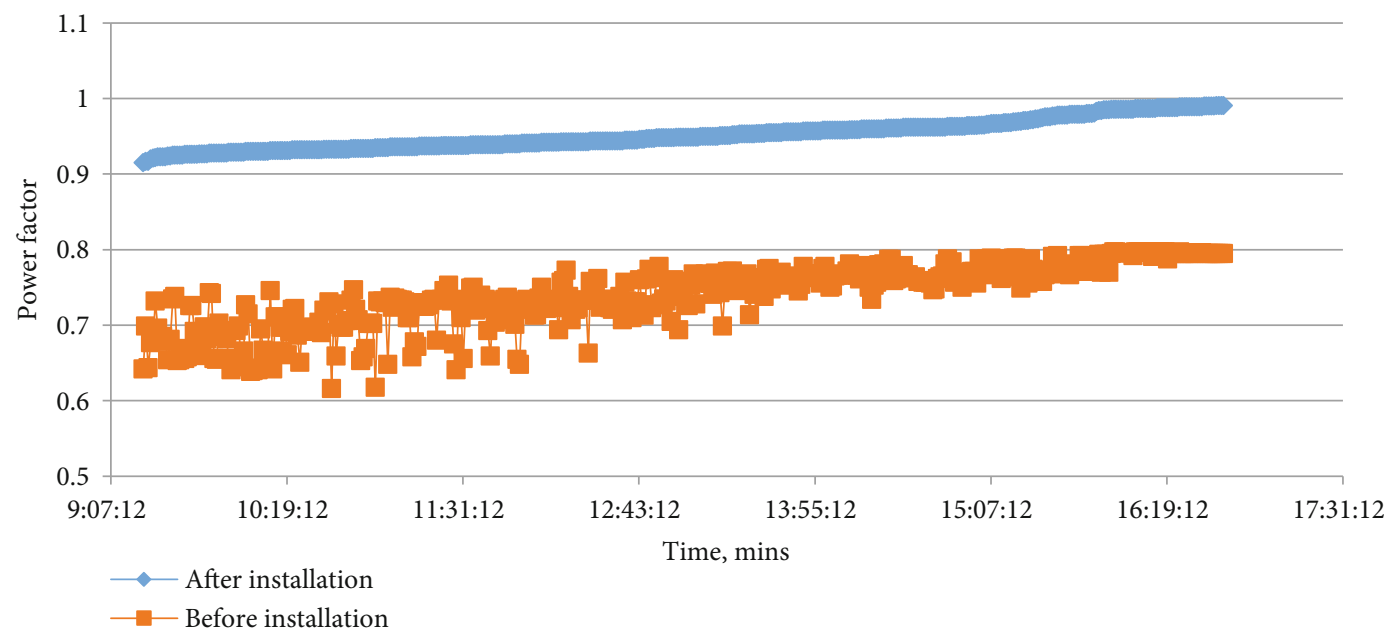

FIgURE 20: Effect of IPFC installation on overall power factor (phase III-postaudit). 


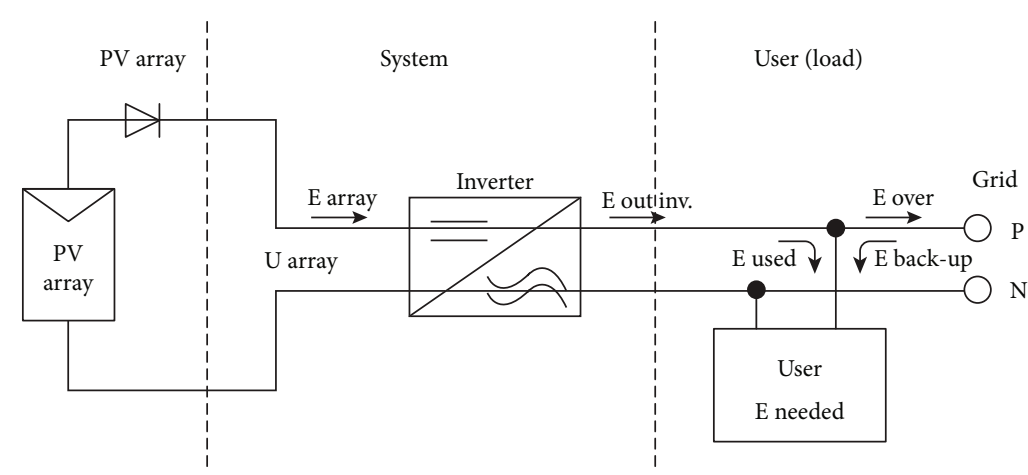

FIGURE 21: Layout of proposed solar photovoltaic plant (Source: PVsyst simulation software).

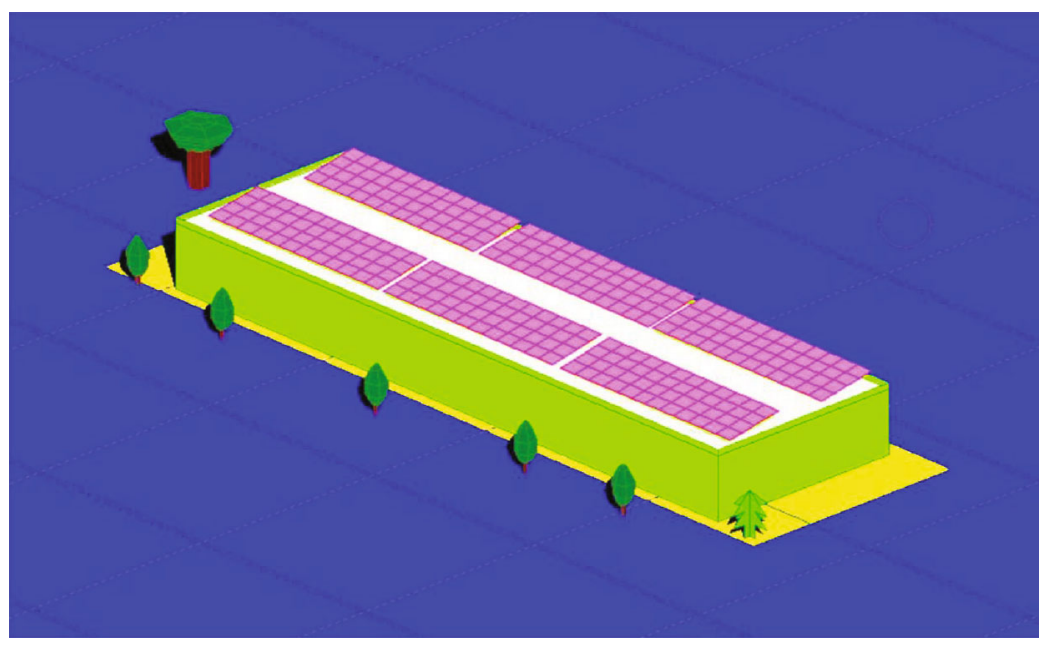

FIGURE 22: Solar Pro 3D CAD modelling of proposed $100 \mathrm{kWp} \mathrm{SPV} \mathrm{plant.}$

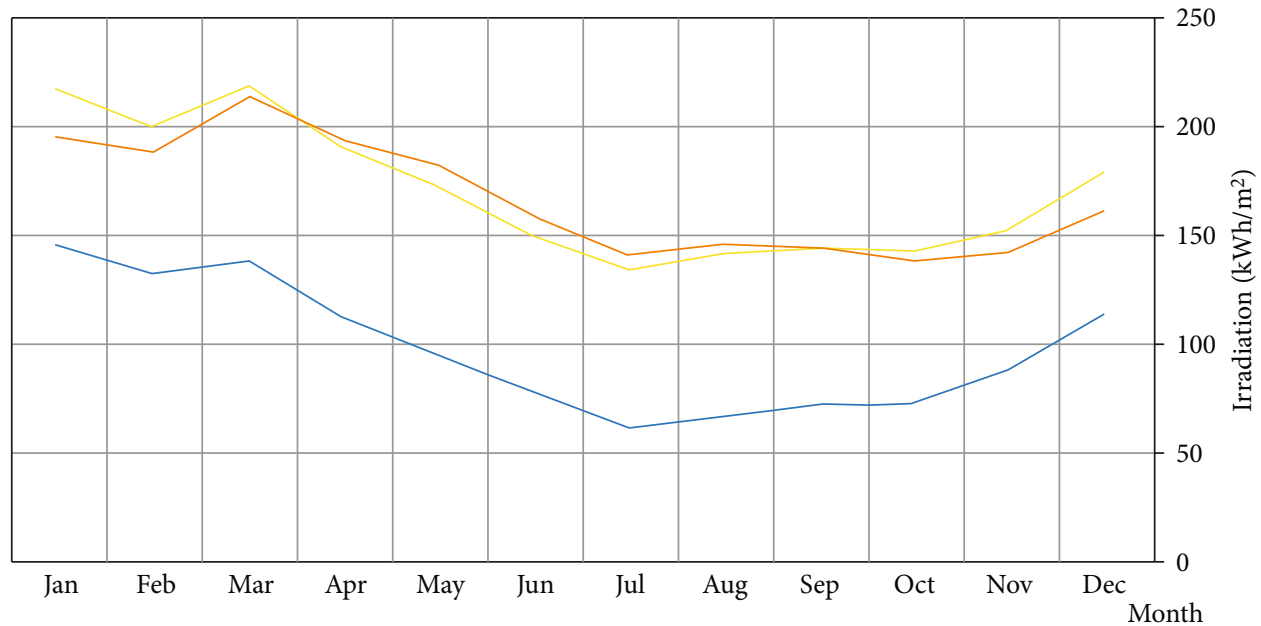

Total irradiation

Horizonta irradiation

- Direct irradiation

FIGURE 23: Month-wise solar irradiation of the proposed SPV plant. 


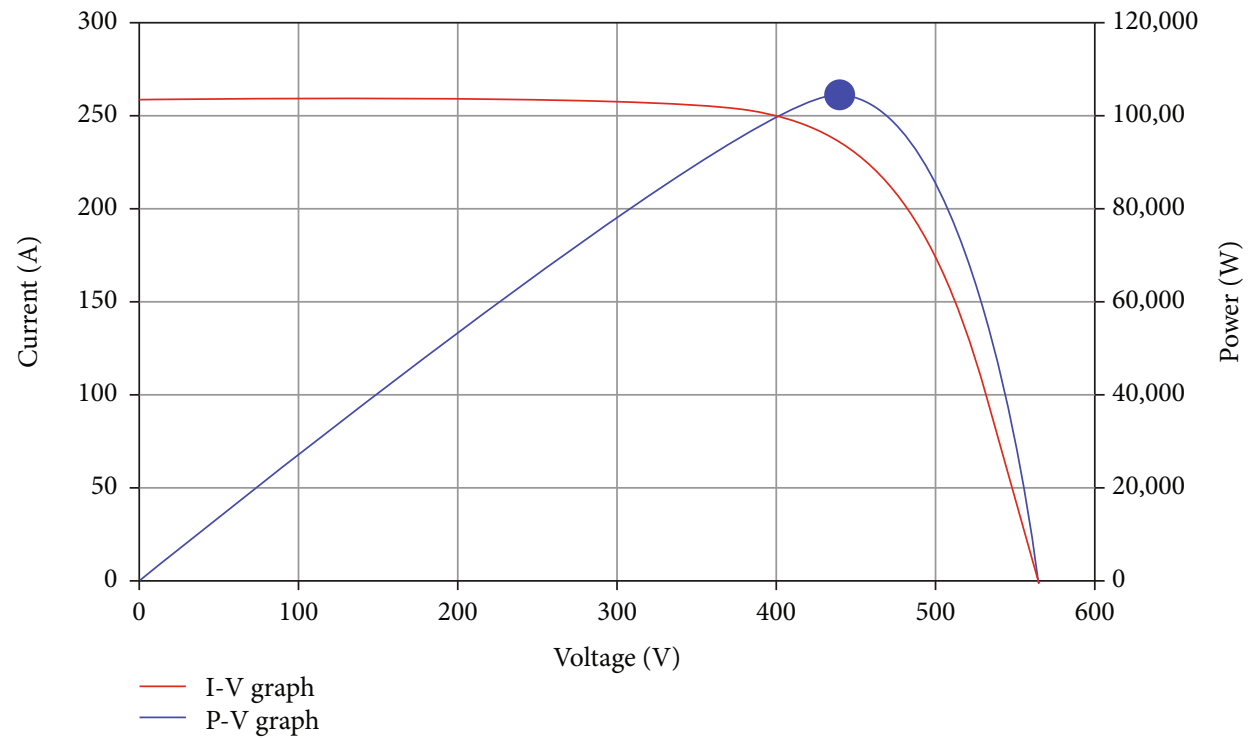

FIGURE 24: Voltage vs. current and power characteristic curve of the proposed SPV plant.

\section{Results and Discussion of the Proposed Solar Photovoltaic Power Plant}

8.1. Power Analysis of the Proposed SPV Plant. Figure 24 illustrates the voltage versus current characteristics of the overall SPV power plant in the primary vertical axis. The manufacturer datasheet provides the following parameters of the module: rated power of $360 \mathrm{Wp}$ solar PV module is powered by the open-circuit voltage of $187.50\left(V_{\mathrm{OC}}\right)$ and short-circuit current of $\left(I_{S C}\right) 2.7 \mathrm{~A}$. The voltage versus power characteristics are shown in the secondary vertical axis of Figure 24. The maximum power point (MPP) is the maximum point at which maximum (or) optimum power generation is ascertained. The maximum voltage and maximum current of $146.2 \mathrm{~V}$ and $2.46 \mathrm{~A}$ are achieved during the Solar Pro simulation software calculation mode.

The effect of the average increase in the ambient temperature is directly proportional to the temperature rise of the SPV module. As per the Standard Test Conditions (STC), the SPV modules perform more effectively at 25 degrees Celsius. The negative temperature coefficient of voltage and power is about $-0.35 \% /{ }^{\circ} \mathrm{C}$ and $-0.45 \% /{ }^{\circ} \mathrm{C}$, respectively [40]. Therefore, the temperature rise directly affects the power output and efficiency [40] of the SPV plants.

Figure 25 illustrates the month-wise solar PV and AC energy generation (power analysis) of the proposed solar photovoltaic power plant. The maximum peak generation of $12,000 \mathrm{kWh}$ is achieved during the month of March with the maximum total irradiation. The power analysis is carried out based on the solar generation and the historical power consumption pattern of the SME under investigation. Therefore, the average generation of $8000 \mathrm{kWh}$ is maintained throughout the year as a positive indicator to move forward into the proposed SPV plant.

8.2. Economic Analysis of the Proposed SPV Plant. The economic analysis of SPV is carried out using the Solar Pro simulation software with the month-wise historical data of SME power consumption. Figure 26 gives the month-wise selling, buying, and bill reduction price of the proposed SPV plant. As per the guidelines and regulations of state and central nodal agencies, the selling price of the SPV power plant is fixed. The higher average annual bill reduction is achieved based on the economic and power analysis due to the maximum SPV power generation, excess power evacuation (power export), and optimized energy utilization of SMEs.

Figure 27 gives the month-wise load energy (i.e., load consumption and AC energy generated by the proposed SPV power plant of SME in the primary vertical axis). The secondary vertical axis gives month-wise cost economics of energy consumption and its bill reduction due to SPV power penetration and power export to the grid. The period from March to May is having the highest SPV generation and bill reduction. The average energy bill reduction (savings) is significantly maintained throughout the year. Figure 28 gives the economic payback period of 7 years on the proposed SPV plant, which is a positive indicator for the proposed SPV power plant.

8.3. Life Cycle Carbon Emission of the Proposed SPV Plant. The life cycle carbon [41] emission of the proposed solar power plant is calculated in detail with the SPV modules, supports (includes the balance of system and other auxiliaries), and inverters. The amount of carbon emission generated from the proposed SPV plant's installation and operation is about $188.61 \mathrm{tCO}_{2}$ for the 30 years lifetime of the SPV plant. Therefore, the replacement carbon emission is based on SPV power generation as per the Central Electricity Authority (CEA) guidelines and regulations.

The carbon emission of grid-interactive SPV is taken, and the replacement emission is calculated as $4694.8 \mathrm{tCO}_{2}$ with the annual SPV power production of 167.17 MWh. The following International Energy Agency (IEA) considerations like the SPV power plant lifespan of 30 years, the $1 \%$ annual degradation, and the grid lifecycle emission of $936 \mathrm{gCO}_{2} / \mathrm{kWh}$ are 


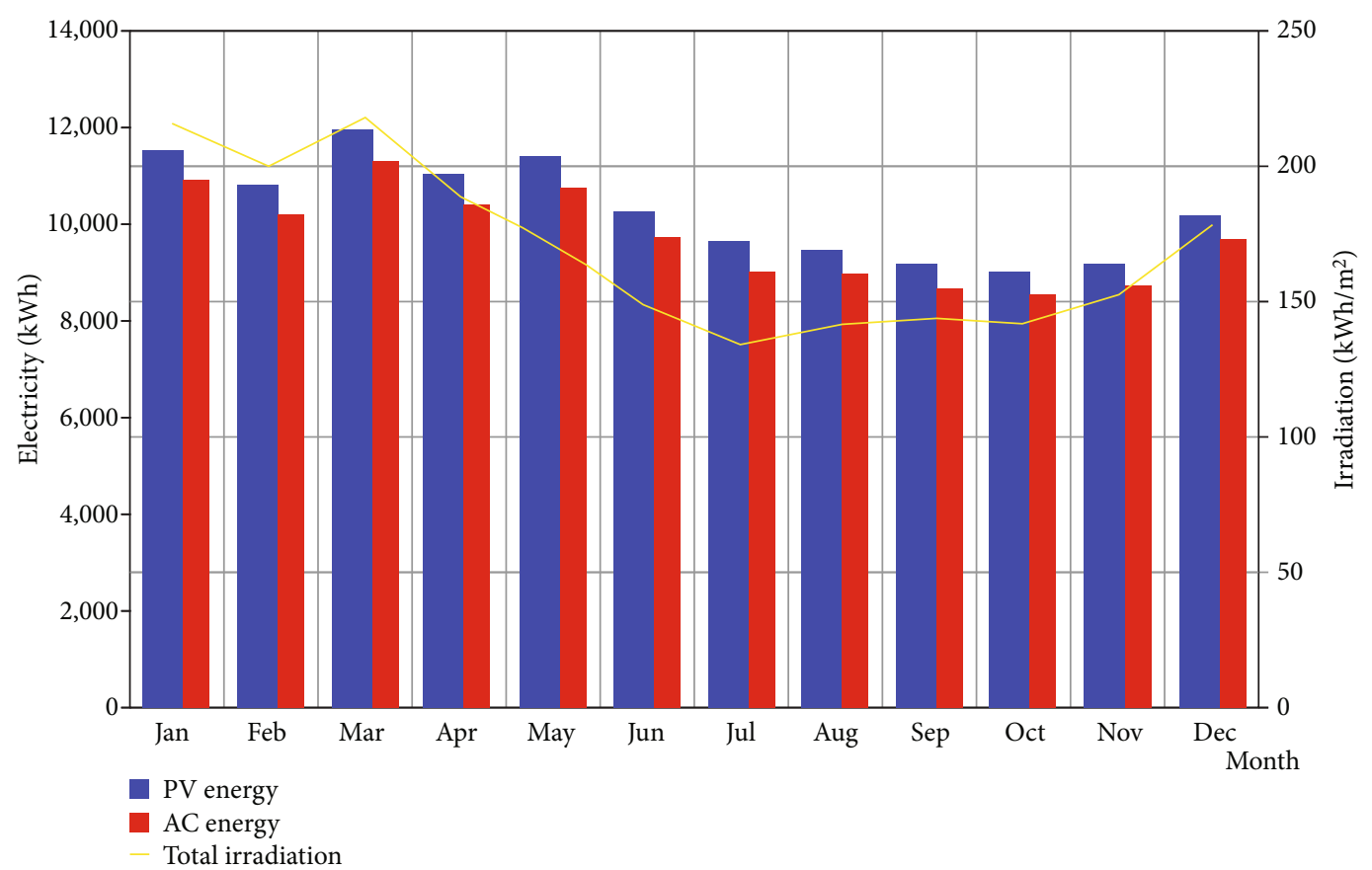

FIGURE 25: Month vs. power analysis of the proposed SPV plant.

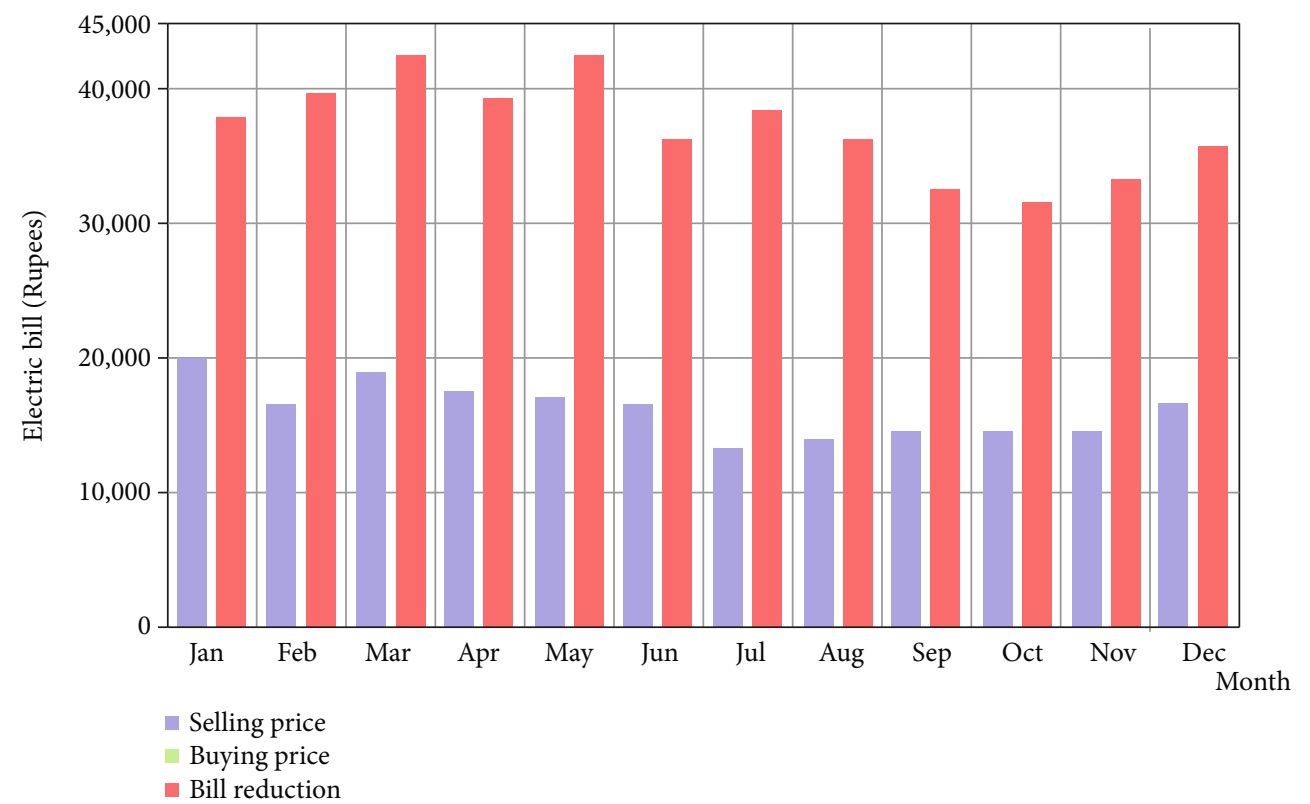

FIGURE 26: Month-wise economic analysis of the proposed SPV plant.

considered for the calculation of $\mathrm{CO}_{2}$ emission balance analysis. Therefore, the resultant $\mathrm{CO}_{2}$ emission balance of 4506.2 $\mathrm{tCO}_{2}$ is achieved from the proposed SPV power plant.

\section{Conclusion}

Complete electrical energy auditing was carried out. Based on the detailed analysis, the following suggestions and recommendations are prepared. The design and installation of $73 \mathrm{KVAr}$ compensator capacitors will enhance the enter- prise's power factor to improve the SME's overall energy efficiency. The effectiveness of IPFC is ensured by $33.33 \%$ current reduction, $28.88 \%$ total power consumption reduction, $27.22 \%$ neutral I-THDF reduction, and a $65 \%$ increase in the overall power factor. Therefore, the effectiveness of installed Intelligent Power Factor Correction (IPFC) panel is highly significant, and it could enable the cost-effective, accurate, and high-performance reactive power compensation by installing the IPFC unit in the point of common coupling (PCC) instead of going with the load side reactive 


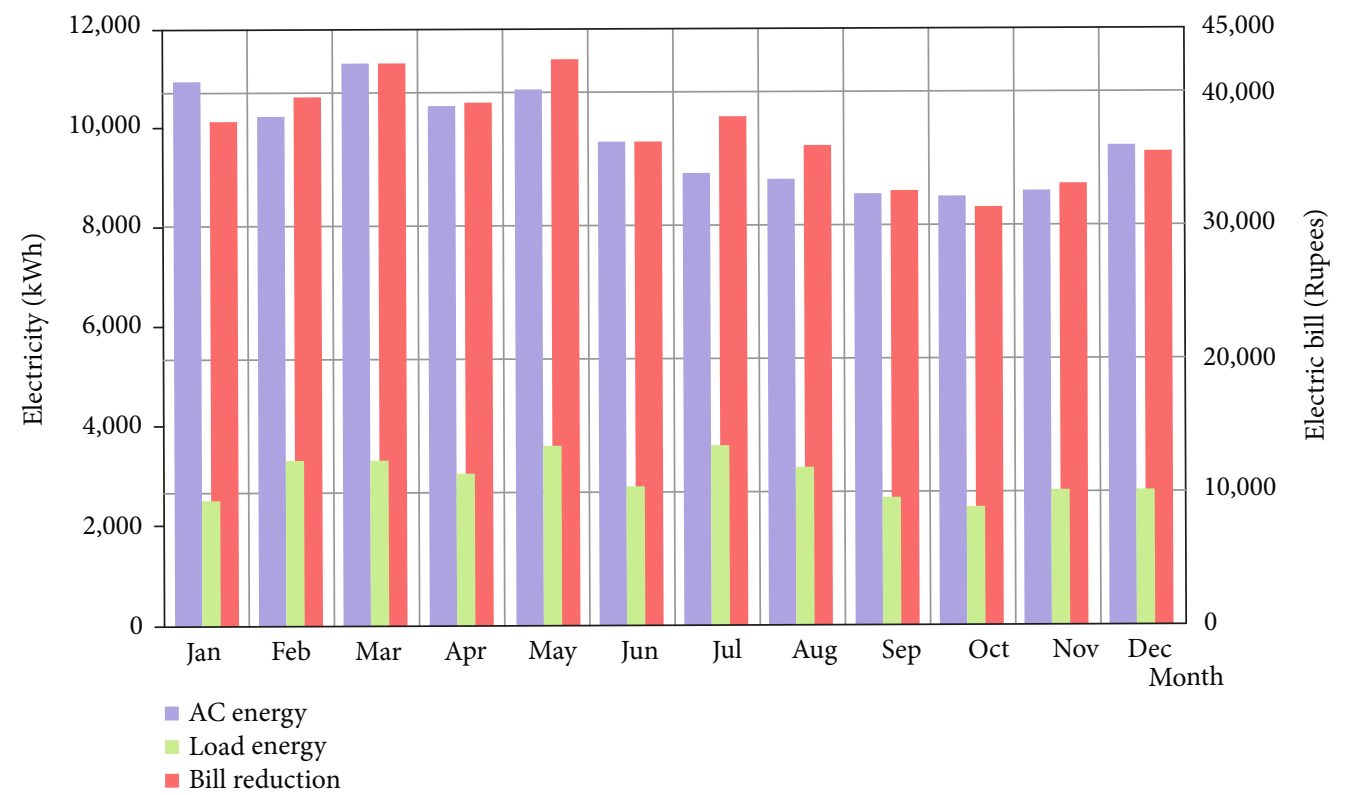

FIGURE 27: Month-wise economic saving of the proposed SPV plant.

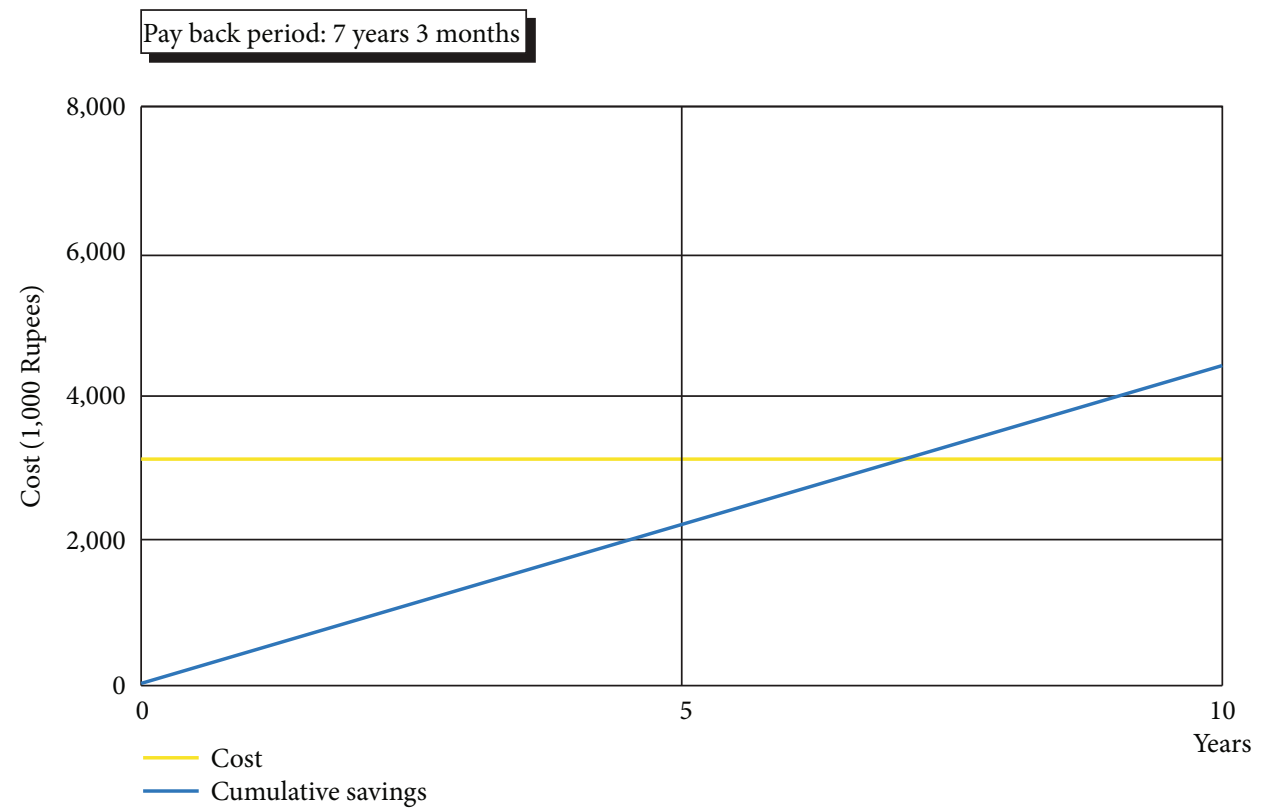

FIGURE 28: Economic payback analysis of the proposed SPV plant.

power compensation to get the desirable compensation. There is a significant reduction in the enterprise's power consumption by installing the IPFC compensator, paving a roadmap to achieve climate change mitigation by reducing carbon dioxide emission by reducing $1296 \mathrm{~kg}$ of $\mathrm{CO}_{2}$ from the electrical power consumption.

From the design of the SPV power plant, the availability of SPV potential, energy, and cost economic performance is highly feasible for SMEs to deploy the SPV power plant. The SPV energy generation and utilization lead to energy bill reduction of SME and additional revenue by exporting the excess power to the grid. The replacement carbon emission of $4694.8 \mathrm{tCO}_{2}$ is possible by the installation of the proposed SPV plant. Therefore, the proposed solar photovoltaic power plant is highly feasible to deploy in the SME for its energy and economic savings with the more significant environmental sustainability for climate change mitigation. Therefore, the energy self-sufficient of SME is highly feasible by the proposed SPV plant in a sustainable manner.

\section{Data Availability}

The data used to support the findings of this study are available from the corresponding author upon request. 


\section{Conflicts of Interest}

The authors declare that there are no conflicts of interest regarding the publication of this paper.

\section{Acknowledgments}

The authors gratefully acknowledge the Department of Science and Technology (DST), India, for financial support under the DST-INSPIRE Fellowship (ID No: IF180435) and the secretary of Lakshmi Seva Sangam, Gandhigram, for providing permission to carry out the analysis.

\section{References}

[1] R. Saidur, "A review on electrical motors energy use and energy savings," Renewable and Sustainable Energy Reviews, vol. 14, no. 3, pp. 877-898, 2010.

[2] F. Kalantzis and D. Revoltella, "Do energy audits help SMEs to realize energy-efficiency opportunities?," Energy Economics, vol. 83, pp. 229-239, 2019.

[3] A. Kubule, K. Ločmelis, and D. Blumberga, "Analysis of the results of national energy audit program in Latvia," Energy, vol. 202, p. 117679, 2020.

[4] P. Thollander, M. Karlsson, P. Rohdin, J. Wollin, and J. Rosenqvist, "Energy auditing ${ }^{1}$," Introduction to Industrial Energy Efficiency, vol. 50, pp. 61-87, 2020.

[5] J. R. Neumann, Ensuring Business Resilience. EDSA Micro Corporation n.d.:1-5, 2020, http://www.poweranalytics.com/pa_ articles/pdf/EnsuringBusinessResilience.pdf.

[6] C. Sreenath, S. Prabhakaran, V. Rajakumaran, C. Shankar, S. S. S. Velan, and V. Kirubakaran, "Energy auditing of payment tiles making small scale industry: suggestions and recommendations for energy conservation," in 2015 International Conference on Circuits, Power and Computing Technologies ICCPCT-2015, pp. 1-4, March 2015.

[7] S. K. Rajput and O. Singh, "Energy audit in textile industry: a study with ring frame motor," in 2016 International Conference on Control, Computing, Communication and Materials (ICCCCM), pp. 1-4, October 2016.

[8] A. L. Divya, C. A. Vigneshwari, M. Damini, M. A. Sabeena, V. Kolambikai, and V. Kirubakaran, "Energy auditing for a farm house10.1109/ICCPCT.2015.7159446," in 2015 International Conference on Circuits, Power and Computing Technologies ICCPCT-2015, pp. 1-6, March 2015.

[9] I. Palcic, M. Pons, A. Bikfalvi, J. Llach, and B. Buchmeister, "Analysing energy and material saving technologies' adoption and adopters/Analiza uporabe in uporabnikov okolju prijaznih tehnologij v proizvodnih podjetjih," Strojniski Vestnik Journal of Mechanical Engineering, vol. 59, 2013.

[10] V. Blass, C. J. Corbett, M. A. Delmas, and S. Muthulingam, "Top management and the adoption of energy efficiency practices: evidence from small and medium-sized manufacturing firms in the US," Energy, vol. 65, pp. 560-571, 2014.

[11] R. Shinde, A. Pathak, and B. Chaughule, "Harmonic analysis and power factor correction for food processing industry," International Journal of Computational Engineering Research, vol. 3, no. 6, pp. 53-58, 2013.

[12] M. Singh, "Environment management systems in Indian small and medium-sized enterprises," Academy of Taiwan Business Management Review, vol. 8, no. 2, pp. 45-55, 2010.
[13] S. S. S. Velan and V. Kirubakaran, "Implementation of energy conservation and management activities and its economics in GRI boy's hostel - a case study," in 2016 Biennial International Conference on Power and Energy Systems: Towards Sustainable Energy (PESTSE), pp. 1-10, January 2016.

[14] P. Thollander, M. Karlsson, P. Rohdin, J. Wollin, and J. Rosenqvist, Energy auditing and measurements in practice. Introduction to Industrial Energy Efficiency, Elsevier, 2020.

[15] G. Dermentzis, F. Ochs, M. Gustafsson et al., "A comprehensive evaluation of a monthly-based energy auditing tool through dynamic simulations, and monitoring in a renovation case study," Energy and Buildings, vol. 183, pp. 713-726, 2019.

[16] Z. De Grève, J. Bottieau, D. Vangulick et al., "Machine learning techniques for improving self-consumption in renewable energy communities," Energies, vol. 13, no. 18, p. 4892, 2020.

[17] J. Schleich and T. Fleiter, "Effectiveness of energy audits in small business organizations," Resource and Energy Economics, vol. 56, pp. 59-70, 2019.

[18] R. Scozzari and M. Santarelli, "Techno-economic analysis of a small size short range EES ( electric energy storage ) system for a PV (photovoltaic) plant serving a SME (small and medium enterprise) in a given regulatory context," Energy, vol. 71, pp. 180-193, 2014.

[19] A. Khoodaruth, V. Oree, M. K. Elahee, and W. W. Clark, "Exploring options for a $100 \%$ renewable energy system in Mauritius by 2050," Utilities Policy, vol. 44, pp. 38-49, 2017.

[20] A. Pechmann and M. Zarte, "Economic analysis of decentralized, electrical- and thermal renewable energy supply for small and medium-sized enterprises," Procedia CIRP, vol. 61, pp. 422-427, 2017.

[21] Ç. Karatuğ and Y. Durmuşoğlu, "Design of a solar photovoltaic system for a Ro-Ro ship and estimation of performance analysis: a case study," Solar Energy, vol. 207, pp. 1259-1268, 2020.

[22] M. Satish, S. Santhosh, and A. Yadav, "Simulation of a Dubai based $200 \mathrm{KW}$ power plant using PVsyst Software," in 2020 7th International Conference on Signal Processing and Integrated Networks (SPIN), pp. 824-847, Febuary 2020.

[23] A. Chauhan, M. Sharma, and S. Baghel, "Designing and performance analysis of 15KWP grid connection photovoltaic system using Pvsyst software," in 2020 Second International Conference on Inventive Research in Computing Applications (ICIRCA), pp. 1003-1008, July 2020.

[24] K. C. Rout and P. Kulkarni, "Design and performance evaluation of proposed $2 \mathrm{~kW}$ solar PV rooftop on grid system in Odisha using PVsyst," in 2020 IEEE International Students' Conference on Electrical,Electronics and Computer Science (SCEECS), pp. 1-6, Febuary 2020.

[25] S. S. Chopade, L. P. Raj, and G. N. Prabakaran, "Bench marking of grid tied solar roof top photovoltaic system: a case comparison," International Journal of Engineering \& Technology, vol. 7, 2018.

[26] N. M. Kumar, M. R. Kumar, P. R. Rejoice, and M. Mathew, "Performance analysis of $100 \mathrm{kWp}$ grid connected Si-poly photovoltaic system using PVsyst simulation tool," Energy Procedia, vol. 117, pp. 180-189, 2017.

[27] L. G. Popa and M. Brumaru, "Optimizing buildings energy performance through photovoltaic panel integration within a mobile shading system," Procedia Manufacturing, vol. 22, pp. 765-772, 2018. 
[28] K. H. Chao and C. T. Chen, "A remote supervision fault diagnosis meter for photovoltaic power generation systems," Measurement: Journal of the International Measurement Confederation, vol. 104, pp. 93-104, 2017.

[29] K.-H. Chao, Y.-W. Chao, and J.-P. Chen, “A circuit-based photovoltaic module simulator with shadow and fault settings," International Journal of Electronics, vol. 103, pp. 424438, 2015.

[30] K. Kamaleswaran, M. Venkateshwaran, P. Harinath, M. A. Mydeen, and V. Kirubakaran, "Energy conservation potential in rural industry: a case study on coir industry," in IEEE International Conference on Circuit, Power and Computing Technologies, ICCPCT 2015, March 2015.

[31] T. Mariprasath and V. Kirubakaran, "Real time harmonic analysis on rural industries," Indian Journal of Science and Technology, vol. 9, no. 2, 2016.

[32] N. R. Kulkami, H. Vijay Murthy, and A. P. Raju, "PLC based intelligent power factor correctors for industrial power systems-a case study," in Proceedings of the 2015 IEEE International Conference on Power and Advanced Control Engineering, ICPACE 2015, pp. 75-79, August 2015.

[33] R. Bayindir, S. Sagiroglu, and I. Colak, "An intelligent power factor corrector for power system using artificial neural networks," Electric Power Systems Research, vol. 79, no. 1, pp. 152-160, 2009.

[34] K. Kamaleswaran, S. Prabhakaran, P. Harinath, M. Damini, and V. Kirubakaran, "Capacity building on energy conservation in rural industries: a case study," in 20163 rd International Conference on Electrical Energy Systems (ICEES), pp. 306-311, March 2016.

[35] Atmel. AT89S52 - Datasheet Microcontroller with 8K Bytes Programmable Flash. Atmel 2001, pp. 1-30, 2020, http:// www.atmel.com/images/doc1919.pdf.

[36] P. Harinath, K. Kamaleswaran, M. Venkateshwaran, C. Sreenath, S. Prabhakaran, and V. Kirubakaran, "A critical analysis of power quality issues in data center," in 2016 Biennial International Conference on Power and Energy Systems: Towards Sustainable Energy (PESTSE), pp. 1-6, January 2016.

[37] M. Ravindran and V. Kirubakaran, "Electrical energy conservation in automatic power factor correction by embedded system," Energy and Power, vol. 2, no. 4, pp. 51-54, 2012.

[38] GOI-MOP, CO2 baseline database for the Indian power sector user guide, vol. 3, Report by Ministry of Power Govt of India 2014, 2020, http://www.indiaenvironmentportal.org.in/files/ file/CO2\%20Baseline\%20Database\%20for\%20the\%20Indian\% 20Power\%20Sector.pdf.

[39] T. N. E. REGULATORY, C. Solar, and On RG, Tamil Nadu Electricity Regulatory Commission, Tamil Nadu State Press 2013, 2020, http://www.tnerc.gov.in/.

[40] P. R. G. N. P. R. G. N. Lalith, G. Prabakaran, A. Murugaiyan, and V. Kirubakaran, "Hybrid photovoltaic-thermal systems: innovative CHP approach," in Proceedings of the 4th International Conference on Electrical Energy Systems, ICEES 2018, pp. 726-730, Febuary 2018.

[41] C. Marimuthu and V. Kirubakaran, "Carbon pay back period for solar and wind energy project installed in India: a critical review," Renewable and Sustainable Energy Reviews, vol. 23, pp. 80-90, 2013. 